\title{
Recent developments in metamodel based robust black-box simulation optimization: An overview
}

\author{
Amir Parnianifard ${ }^{a^{*}}$, A.S. Azfanizam ${ }^{a}$, M.K.A. Ariffin ${ }^{a}$, M.I.S. Ismail ${ }^{a}$ and Nader Ale Ebrahim ${ }^{b}$
}

${ }^{a}$ Department of Mechanical and Manufacturing Engineering, Faculty of Engineering, Universiti Putra Malaysia, 43400 UPM Serdang, Selangor, Malaysia

${ }^{b}$ Center for Research Services, Institute of Research Management and Monitoring (IPPP), University of Malaya, Kuala Lumpur, Malaysia

\begin{tabular}{l}
\hline C H R O N I C L E \\
\hline Article history: \\
Received January 18, 2018 \\
Received in revised format: \\
May 10, 2018 \\
Accepted May 11, 2018 \\
Available online \\
May 23, 2018 \\
\hline Keywords: \\
Simulation optimization \\
Robust design \\
Metamodel \\
Polynomial regression \\
Kriging \\
Computer experiments
\end{tabular}

\begin{abstract}
A B S T R A C T
In the real world of engineering problems, in order to reduce optimization costs in physical processes, running simulation experiments in the format of computer codes have been conducted. It is desired to improve the validity of simulation-optimization results by attending the source of variability in the model's output(s). Uncertainty can increase complexity and computational costs in Designing and Analyzing of Computer Experiments (DACE). In this state-of the art review paper, a systematic qualitative and quantitative review is implemented among Metamodel Based Robust Simulation Optimization (MBRSO) for black-box and expensive simulation models under uncertainty. This context is focused on the management of uncertainty, particularly based on the Taguchi worldview on robust design and robust optimization methods in the class of dual response methodology when simulation optimization can be handled by surrogates. At the end, while both trends and gaps in the research field are highlighted, some suggestions for future research are directed.
\end{abstract}

\section{Introduction}

Nowadays, developing processes in an engineering world is strongly associated with computer simulations. These computer codes can collect appropriate information about characteristics of engineering problems before actually running the process. Computer simulations can help a rapid investigation of various alternative designs to decrease the required time to improve the system. In addition, most numerical analyses for engineering problems make a well-suited use of mathematical programming. Clearly, a Simulation-Optimization (SO) becomes necessary to find more interest and popularity than other optimization methods, in order to the complexity of many real world optimization problems in way of mathematical formulation analyzing (Dellino et al., 2014). The main goals of simulation can be defined as two, first what-if study of model or sensitivity analysis, and second is optimization and validation of model (van Beers \& Kleijnen, 2003). The essential benefit of simulation is its ability to cover complex processes, either deterministic or random while eliminating mathematical sophistication (Figueira \& Almada-Lobo, 2014).

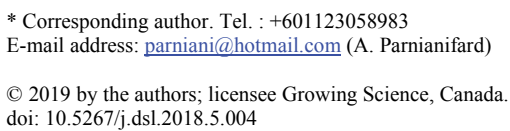




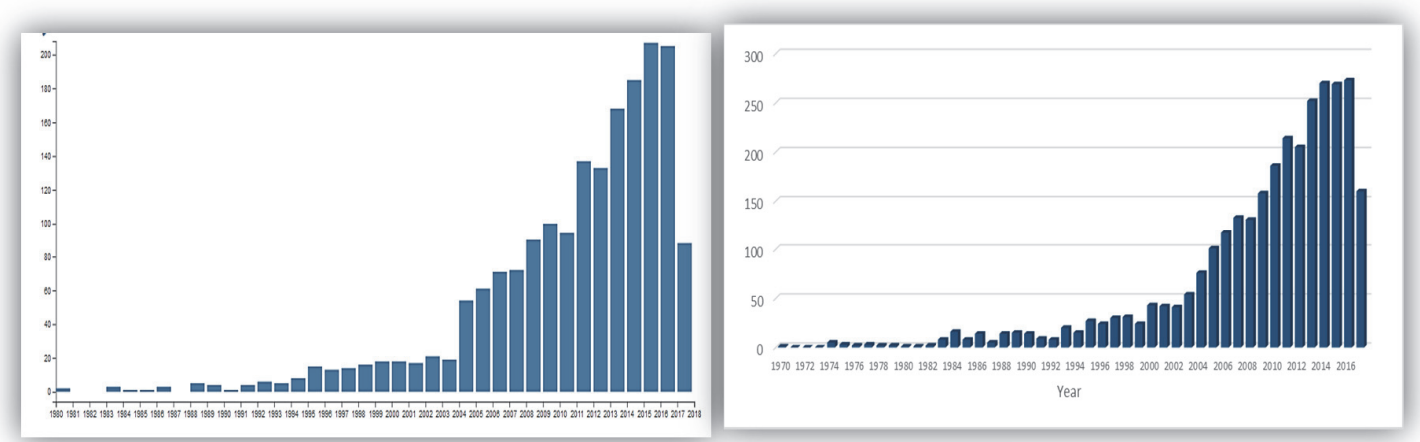

(a)

(b)

Fig. 1. The trend of publications with topic of "simulation optimization" in (a) the Web of Science databases (source: WoS, Data retrieved on August 2017), and (b) SCOPUS (source: Scopus, Data retrieved August 2017).

In general, SO techniques are classified into model-based and metamodel-based (Mohammad Nezhad \& Mahlooji, 2013; Viana et al., 2014). In the model-based, the simulation running is not expensive and model output can be used directly in optimization. Many large scales and detailed simulation models in the complex system particularly under uncertainty may be expensive to run in terms of timeconsuming, computational cost, and resources. Moreover, to address such a challenge, metamodels need to be derived via combing by robust design optimization.

The trend of publications on the topic of "simulation optimization" in both Web of Science and SCOPUS databases are confirming the interest on the search term, see Fig.1. On the other hand, an internet search by using a popular web browser "Google Scholar" returns over 40,300 pages, which mainly containing scientific and technical articles, research reports, conference publications, and academic manuscript.

In this paper, we follow to review the latest developments in Metamodel-Based Simulation Optimization (MBSO) and in wider scope, Metamodel-Based Robust Simulation Optimization (MBRSO) when simulation affected from uncertainty in model's parameters. MBRSO is applied in the complex simulation model under uncertainty when simulation running is expensive in terms of computational time and/or cost, therefore the just limited number of simulation running is possible.

The rest of this review is organized as follows. Section 2 covers quantitative analysis and also illustrates the survey method while highlight the method of gathering and reviewing articles. In section 3, qualitative analysis is provided including the relevant basic approaches and methodologies around the MBRSO. Section 4 discusses remarkable research findings and provides the main recommendations which are extracted throughout reviewing the literature. The paper is concluded in section 5 with summarizing important research tips.

\section{Quantitative analysis on metamodel based simulation optimization}

SciVal offers quick, easy access to the research performance of 8,500 research institutions and 220 nations around the world (see "About SciVal" in Elsevier 2017'). Visualization of Elsevier's SCOPUS data for the selected search terms "Visibility" and "Citations" is provided by SciVal. Being the largest abstract and reference database, SCOPUS provides citation dataset of research literature and quality web sources (Aghaei Chadegani et al., 2013). Fig. 2 shows the publications trend on "Metamodel" and "simulation optimization" impact 1996 to date (12 September 2017). The number of publication on the topic has increased from one publication in the year 2006 to 65 publications in 2016. In order to forecast the trend of scholarly outputs in following years, we fit polynomial regression over data in

. Elsevier. (2017). About SciVal. Retrieved from https://www.elsevier.com/solutions/scival 
when $x$ is year and $y$ is the number of annual documents. In the last six years 659 papers were published, receiving over 10,503 views, 2,465 citations, 147 international collaborations, and 1.36 Field-Weighted Citation Impact (FWCI). The FWCI is a measure of citation impact that normalizes for differences in citation activity by subject field, article type, and publication year (Jang \& Kim, 2014). The world's average for FWCI is indexed at 1.00, as such, values above 1.00 indicate an above average citation impact. Specifically, a citation impact of 1.36 indicates $36 \%$ of the citations are above the average citations in this same filed.

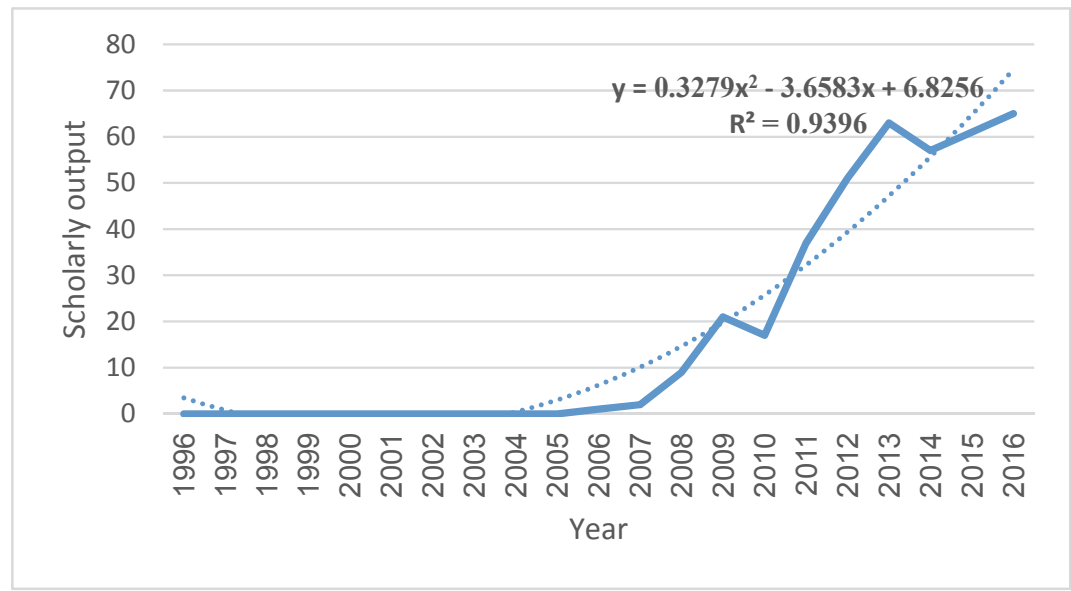

Fig. 2. Trend of publications on "Metamodel and simulation optimization" impact (data from 1996 to date)

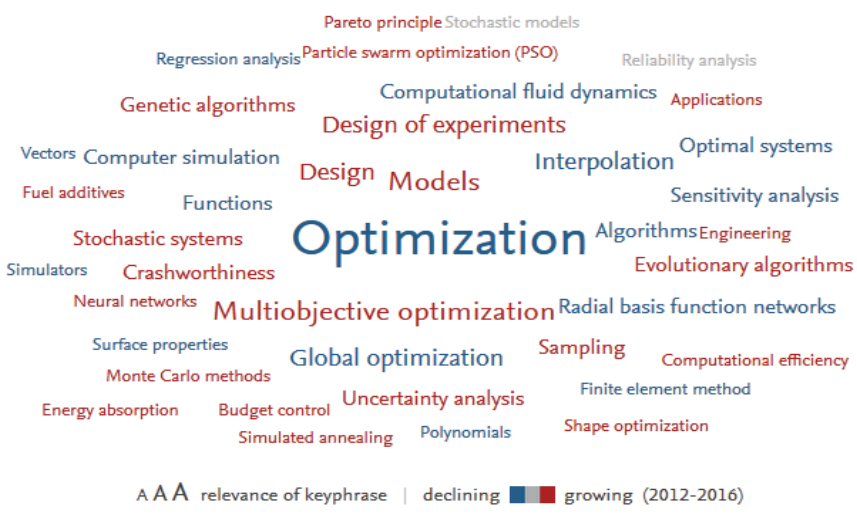

Fig. 3. The top 50 key-phrases by relevance in the past five years papers (656 publication)

The top 50 key-phrases by relevance for the past five years publications ( 656 publication) is shown in Fig. 3. Notably, the phrases "optimization" are the most repeated keyword. The highlighted importance of the key phrases of "interpolation", "computer simulation", and global optimization" are obvious. In addition, the phrase of "design of experiments", "multi-objective optimization", and "uncertainty analysis" among the most repeated keywords in recent publications which gained growing attentions. The trends of publications and the top $50 \mathrm{key}$-phrases have proven the importance of current research on in scholarly publications. Therefore, there is an interest to find alternative ways to improve research on simulation optimization, such as combining design of experiments by evolutionary algorithms like expected improvement methodology which today become to be interested among academic research world, for instance see (Havinga et al., 2017; Zhang et al., 2017). According to associated obtained data from SciVal among search on metamodel and simulation optimization, the top ten countries, authors, and journals which ranked based on views count (views source: Scopus data up to 31 Jul 2017) are respectively sketched in Table 1, Table 2 and Table 3. 
Table 1

Top ten high view counts countries in field MBSO.

\begin{tabular}{lllll}
\hline No & Country & Views Count & Scholarly Output & FWCI \\
\hline 1 & United States & 2166 & 154 & 1.63 \\
2 & China & 1837 & 145 & 1.04 \\
3 & France & 927 & 58 & 1.52 \\
4 & Italy & 907 & 39 & 3.66 \\
5 & Iran & 629 & 30 & 1.19 \\
6 & United Kingdom & 549 & 31 & 2.63 \\
7 & Germany & 487 & 42 & 1.02 \\
8 & Netherlands & 480 & 21 & 2.09 \\
9 & South Korea & 422 & 22 & 1.02 \\
10 & Canada & 353 & 22 & 0.81 \\
\hline
\end{tabular}

Table 2

Top ten high view counts authors in field MBSO.

\begin{tabular}{llllll}
\hline No & Author & Affiliation & $\begin{array}{l}\text { Views } \\
\text { Count }\end{array}$ & $\begin{array}{l}\text { Scholarly } \\
\text { Output }\end{array}$ & FWCI \\
\hline 1 & Kleijnen, Jack P.C. & Tilburg University & 205 & 7 & 4.34 \\
2 & Toropov, Vassili V. & University of Leeds & 193 & 7 & 7.83 \\
3 & Sudret, Bruno & ETH Zurich & 179 & 5 & 4.76 \\
4 & Wen, Guilin & Hunan University & 176 & 9 & 2.15 \\
5 & van den Boogaard, A. H. & University of Twente & 170 & 5 & 1.15 \\
6 & Wiebenga, J. H. & Materials Innovation Institute & 170 & 5 & 1.15 \\
7 & Yin, Hanfeng & Hunan University & 167 & 8 & 2.33 \\
8 & Qing, Qixiang & Hunan University & 158 & 5 & 3.83 \\
9 & Shao, Xinyu & Huazhong University of Science and & 129 & 9 & 2.17 \\
10 & Jiang, Ping & Technology & 122 & 6 & 2.07 \\
\hline
\end{tabular}

Table 3

Top ten high view counts journals in field MBSO.

\begin{tabular}{lllll}
\hline No & Country & $\begin{array}{l}\text { Views } \\
\text { Count }\end{array}$ & $\begin{array}{l}\text { Scholarly } \\
\text { Output }\end{array}$ & FWCI \\
\hline 1 & Structural and Multidisciplinary Optimization & 448 & 23 & 1.49 \\
2 & 53rd AIAA/ASME/ASCE/AHS/ASC Structures, & 332 & 4 & 0.77 \\
3 & Structural Dynamics and Materials Conference 2012 & & 6 & 7.63 \\
4 & Advances in Intelligent Systems and Computing & 274 & 6 & 0 \\
5 & WIT Transactions on Engineering Sciences & 240 & 2 & 0 \\
6 & Advanced Materials Research & 239 & 3 & 4.3 \\
7 & European Journal of Operational Research & 217 & 4 & 2.77 \\
8 & International Journal of Impact Engineering & 202 & 4 & 1.22 \\
9 & Engineering Optimization & 198 & 10 & 1.69 \\
10 & Expernable Energy & 196 & 2 & 3.02 \\
\hline
\end{tabular}

\subsection{Instruction of current research}

In the current systematic literature review, the search strategy was as follow s. Some common electronic databases (Scopus indexed) were applied in search processes such as Science Direct, IEEE Xplore, Springer Link, etc. Different keywords and their combinations were used to search the relevant resources in literature from mentioned electronic databases. The SCOPUS databases cover almost two times more than the Web of Science journals (Aghaei Chadegani et al., 2013). Therefore, the SCOPUS 
database was selected as a reference for academic documents source. Table 4 illustrates the number of document results from Scopus by employing some relevant keywords with conjunction 'AND'. The search was conducted on each article title, abstract, and keywords. There are a different number of SO methods that discussion about most of them is beyond of this context. Instead, we focus on simulationoptimization under uncertainty by employing metamodels and robust optimization.

\section{Table 4}

Number of document results based on combination of different keywords (Scopus database).

\begin{tabular}{lllllllllllll}
\hline ID & Keyword & \multicolumn{70}{c}{ Combination of keywords with conjunction 'AND' } \\
\hline 1 & Simulation & $\sqrt{ }$ & $\sqrt{ }$ & $\sqrt{ }$ & $\sqrt{ }$ & $\sqrt{ }$ & $\sqrt{ }$ & $\sqrt{ }$ & $\sqrt{ }$ & $\sqrt{ }$ \\
2 & Optimization & $\sqrt{ }$ & $\sqrt{ }$ & $\sqrt{ }$ & $\sqrt{ }$ & $\sqrt{ }$ & $\sqrt{ }$ & $\sqrt{ }$ & $\sqrt{ }$ & $\sqrt{ }$ \\
3 & Metamodel & $\sqrt{ }$ & $\sqrt{ }$ & $\sqrt{ }$ & & & & & & \\
4 & Response surface & & & & $\sqrt{ }$ & $\sqrt{ }$ & $\sqrt{ }$ & & & \\
5 & Kriging & & & & & & & $\sqrt{ }$ & $\sqrt{ }$ & $\sqrt{ }$ \\
6 & Uncertainty & & $\sqrt{ }$ & & & $\sqrt{ }$ & & & $\sqrt{ }$ & \\
7 & Robust design & & & $\sqrt{ }$ & & & $\sqrt{ }$ & & & $\sqrt{ }$ \\
\hline Total results & 512 & 86 & 29 & 2,710 & 279 & 94 & 1,124 & 208 & 42 \\
Results in range of 2000-2017 & 493 & 86 & 29 & 2,523 & 270 & 89 & 1,106 & 205 & 42 \\
\hline
\end{tabular}

Particular metamodels concentrated are polynomial regression methodology (also called Response Surface Method (RSM)) and Kriging surrogate model. In general, the whole findings were filtered based on three factors, i) selecting articles which are associated to interesting our topic (polynomial regression, Kriging, robust design, and SO), ii) recent articles are preferred (all articles were published after 2000 , when around $60 \%$ of them were published between 2010-Spetember 2017, iii) number of citations are attended. Notably, there are a different number of papers and electronic resources related to the topic, but we just filtered resources which can cover basic knowledge around simulationoptimization via robust design integrating metamodels. So, remarkable findings are concluded into 5 books (Del Castillo, 2007; Dellino \& Meloni, 2015; Fang et al., 2006; Kleijnen, 2015; Myers et al., 2016), 3 Ph.D thesis (Dellino, 2008; Jurecka, 2007; Rutten, 2015), and 60 articles (16 review papers and 41 research papers and 3 chapters). Table 5 shows the identifier of articles while are sorted based on publishing year. Note that the citations were counted from Scopus leading up to April 2017. In this context, articles were reviewed based on seeking in methodology and scope of applicability, while focused on methods, techniques, and approaches which employed to achieve their relevant goal(s).

\section{Qualitative analysis on MBRSO}

The black-box and also computationally expensive simulation models are often found in engineering and science disciplines. Expensive simulation running and expensive analysis of processes are often considered black-box function. In general surrogate models treat the simulation model as a black-box model (Beers \& Kleijnen, 2004; Kleijnen, 2005; Shan \& Wang, 2010). In fact, many simulationoptimization approaches solely depend on such input-output data in investigating of optimal input settings, while in the black box feature, the simulation just permits the evaluation of the objective and constraint for a specific input (Amaran et al., 2016). Moreover, methodologies which are mentioned in this paper can be applied in the class of black-box problems, since it does not need to identify expression or internal structure of the system, and just analyzing output with given list of inputs. Investigating in literature particularly in recent years has been confirmed that application of metamodels in SO is more interested than other methods due to increasing complexity in real systems while they need to be approximated by cheaper methods. In this context, all studies which were investigated among reviewing of literature, are focused on SO techniques via surrogate models. This paper covered more the stochastic simulation-optimization hybrid metamodels (e.g. polynomial regression and Kriging). It is notable that all topics which are explained in continue, are presented to show recent methodological development in analyzing, optimizing and improving complex systems under uncertainty through their 
relevant simulation models by employing some main statistical and mathematical techniques (e.g. robust design optimization and surrogate models as two basic methodologies).

Table 1

Identifiers of articles ("Rev." means review paper, "Res." means research paper, and "Cha." means chapter).

\begin{tabular}{|c|c|c|c|c|c|c|c|}
\hline ID & Type & Reference & Citation & ID & Type & Reference & Citation \\
\hline$\overline{\mathrm{R} 1}$ & Rev. & (Simpson et al., 2001) & 990 & R31 & Res. & (Kleijnen, 2010) & 3 \\
\hline $\mathrm{R} 2$ & Res. & (Simpson et al., 2001) & 529 & $\mathrm{R} 32$ & Res. & (Wiebenga et al., 2012) & 17 \\
\hline R3 & Rev. & (Jin et al., 2001) & 804 & R33 & Res. & (Chang et al., 2013) & 4 \\
\hline $\mathrm{R} 4$ & Res. & (Abspoel et al., 2001) & 10 & R34 & Res. & (Kleijnen \& van Beers, 2013) & 5 \\
\hline R5 & Res. & (Kleijnen \& Gaury, 2003) & 35 & $\mathrm{R} 35$ & Res. & (Zhang et al., 2013) & 7 \\
\hline R6 & Res. & (Truong \& Azadivar, 2003) & 29 & $\mathrm{R} 36$ & Res. & (Dellino et al., 2012) & 26 \\
\hline R7 & Res. & (Wang, 2003) & 207 & $\mathrm{R} 37$ & Res. & (Dellino et al., 2014) & 1 \\
\hline $\mathrm{R} 8$ & Rev. & (Jin et al., 2003) & 173 & $\mathrm{R} 38$ & Res. & (Zhang et al., 2014) & 11 \\
\hline R9 & Rev. & (Chen et al., 2003) & 29 & R39 & Res. & (Uddameri et al., 2014) & 3 \\
\hline $\mathrm{R} 10$ & Res. & (van Beers \& Kleijnen, 2003) & 100 & $\mathrm{R} 40$ & Res. & (Cozad et al., 2014) & 29 \\
\hline $\mathrm{R} 11$ & Res. & (Lehman et al., 2004) & 20 & R41 & Rev. & (Viana et al., 2014) & 69 \\
\hline $\mathrm{R} 12$ & Rev. & (Beers \& Kleijnen, 2004) & 49 & $\mathrm{R} 42$ & Rev. & (Figueira \& Almada-Lobo, 2014) & 31 \\
\hline $\mathrm{R} 13$ & Res. & (Kleijnen \& Beers, 2004) & 118 & $\mathrm{R} 43$ & Cha. & (Dellino et al., 2015) & 0 \\
\hline $\mathrm{R} 14$ & Rev. & (Kleijnen, Jack P. C., 2005) & 154 & R44 & Rev. & (Jalali \& Van Nieuwenhuyse, 2015) & 6 \\
\hline $\mathrm{R} 15$ & Cha. & (Barton \& Meckesheimer, 2006) & 103 & R45 & Res. & (Taflanidis \& Medina, 2015) & 0 \\
\hline $\mathrm{R} 16$ & Res. & (Williams et al., 2006) & 31 & $\mathrm{R} 46$ & Res. & (Kamiński, 2015) & 2 \\
\hline $\mathrm{R} 17$ & Rev. & (Wang \& Shan, 2007) & 685 & R47 & Res. & (Sreekanth et al., 2016) & 4 \\
\hline $\mathrm{R} 18$ & Res. & (Jurecka et al., 2007) & 13 & $\mathrm{R} 48$ & Rev. & (Amaran et al., 2016) & 1 \\
\hline R19 & Res. & (Stinstra \& den Hertog, 2008) & 23 & R49 & Res. & (Li et al., 2016) & 2 \\
\hline $\mathrm{R} 20$ & Res. & (Wim et al., 2008) & 43 & R50 & Res. & (Han \& Yong Tan, 2016) & 0 \\
\hline $\mathrm{R} 21$ & Res. & (Dellino et al., 2009) & 21 & R51 & Rev. & (Haftka et al., 2016) & 3 \\
\hline $\mathrm{R} 22$ & Rev. & (Kleijnen, 2009b) & 331 & R52 & Res. & (Leotardi et al., 2016) & 0 \\
\hline $\mathrm{R} 23$ & Res. & (Steenackers et al., 2009) & 11 & R53 & Res. & (Sathishkumar \& Venkateswaran, 2016) & 0 \\
\hline $\mathrm{R} 24$ & Cha. & (Kleijnen, 2009a) & 3 & R54 & Res. & (Moghaddam \& Mahlooji, 2016) & 0 \\
\hline $\mathrm{R} 25$ & Res. & (Dellino et al., 2009) & 25 & R55 & Res. & (Javed et al., 2016) & 0 \\
\hline $\mathrm{R} 26$ & Res. & (Dellino et al., 2010) & 43 & R56 & Rev. & (Kleijnen, 2017) & 1 \\
\hline $\mathrm{R} 27$ & Res. & (Dellino et al., 2010b) & 3 & R57 & Res. & (Khoshnevisan et al., 2017) & 0 \\
\hline $\mathrm{R} 28$ & Res. & (Dellino et al., 2010a) & 1 & R58 & Res. & (Zhou et al., 2017) & 0 \\
\hline R29 & Res. & (Kuhnt \& Steinberg, 2010) & 6 & R59 & Res. & (Havinga et al., 2017) & 0 \\
\hline $\mathrm{R} 30$ & Rev. & (Li et al., 2010) & 44 & R60 & Res. & (Zhang, 2017) & 0 \\
\hline
\end{tabular}

\subsection{Simulation-optimization (SO)}

The process of investigating the best value of input variables among all possibilities in a simulation model is Simulation-Optimization (SO), also known as an optimization via simulation or simulationbased optimization. The objective of SO is to obtain the optimum value for output while minimizing the resource spent. Kleijnen (2015) have described simulation model as a dynamic or static model that could be solved by means of experimentation. Generally, there are two types of simulation models. The first type is a physical model which describes model's characterization in a smaller dimension (for example, miniature airplane in a wind tunnel). The second type is a mathematical model which usually coded into computer programs. The term dynamic illustrates parameters of the model which are variated over time while in the static model the time does not play an important role. The simulation model often is studied by a mathematical model. The system behavior is evaluated by running the simulation model for a fixed period of time. Generally, a study in simulation techniques can be concentrated into two main parts, first simulation modeling, and second simulation-optimization (see Fig. 4). With optimization strategy, the feedback on the process is provided by the output of simulation model (Carson \& Maria, 1997). In the modeling part, the method can be used to identify process components and select them to design simulation model (Banks et al., 2010; Neelamkavil, 1987). The SO can be attracted the attention of many researchers in improving practical engineering problems via different methods. Azadivar (1999) has compared some common SO methods included gradient based 
search methods, stochastic approximation methods, sample path optimization, response surface methodology, and heuristic search methods.

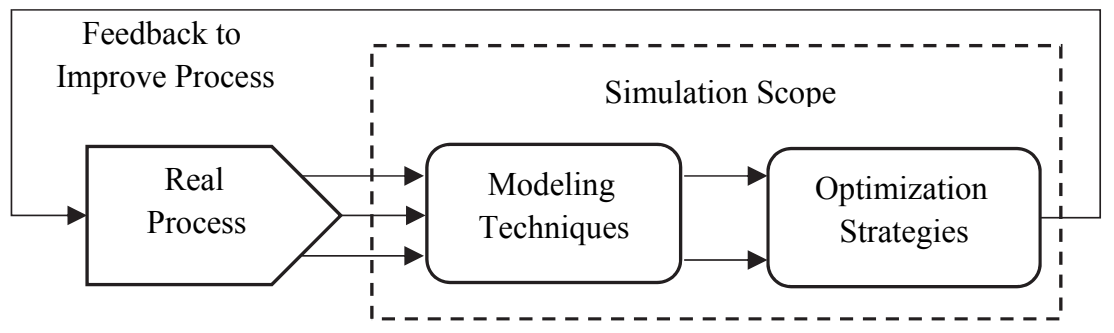

Fig. 4. An overview of simulation scope.

Figueira and Almada-Lobo (2014) have reviewed recent development on SO and classified latest approaches based on four key aspects, simulation purpose, hierarchical structure, search scheme and search method. Other recent studies over SO methods can be found in two books (Dellino \& Meloni, 2015; Kleijnen, 2015) and four review papers (Barton, 1992; Carson \& Maria, 1997; Li et al., 2010; Simpson, Poplinski et al., 2001). In general, SO models can be divided into two types of stochastic and deterministic models (Fig. 5 ).

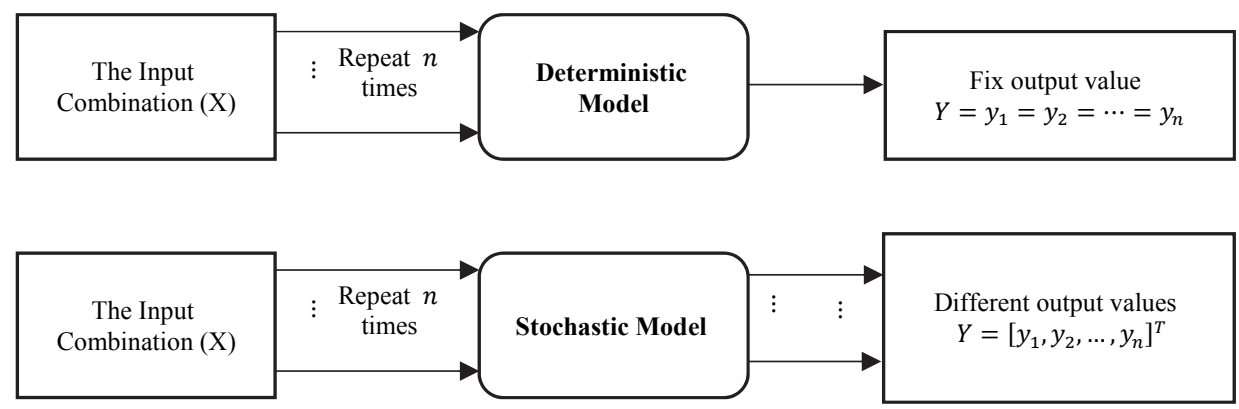

Fig. 5. Deterministic and stochastic simulation models

In deterministic models, a response of model lacks random error, or in another mean, repeated runs for the same design of input parameters, the same result for the response can be gain from the model. Examples of the deterministic simulation are models of airplanes, automobiles, TV sets, and computer chips applied in Computer Aided Engineering (CAE) and Computer Aided Design (CAD) at Boeing, General Motors, Philips, etc.(Kleijnen, 2009b). On the other hand, the output in stochastic or random simulation usually follows some probability distribution which may vary around its space. So, running simulation for the same input combination gives different outputs. Examples are models of logistic and telecommunication systems (Kleijnen, 2009b). This noisy condition of output also enhances optimization challenge, while it becomes harder to distinguish the best set of input variables, and their validity in deterministic approaches are lost. In SO usually we cannot distinguish the exact (deterministic) solution for the black-box system, so we look for the mean and the variance obtained from the sampling points (Amaran et al., 2016). Polynomial regression can sufficiently support both deterministic and random simulation, but Kriging has hardly been used in stochastic simulation (van Beers \& Kleijnen, 2003). In other classification, Amaran et al. (2016) have categorized SO algorithms based on local or global optimal solution (Fig. 6). Barton and Meckesheimer (2006) have classified SO approaches depending on the nature of design variables types. Design variables in simulation models can be either continues and discrete, (see Fig. 7). Continues variables can take any real value within a 
given range which is imposed by constraints. In most engineering problems, during the optimization process with approximation methods (metamodels), the discrete patterns of input variables are neglected and all variables can vary continuously due to solving continues patterns easier. Moreover, based on the optimum design in the continuous feature, the values which inherently are discrete exist, and can be adjusted to the nearest feasible discrete value (Jurecka, 2007).

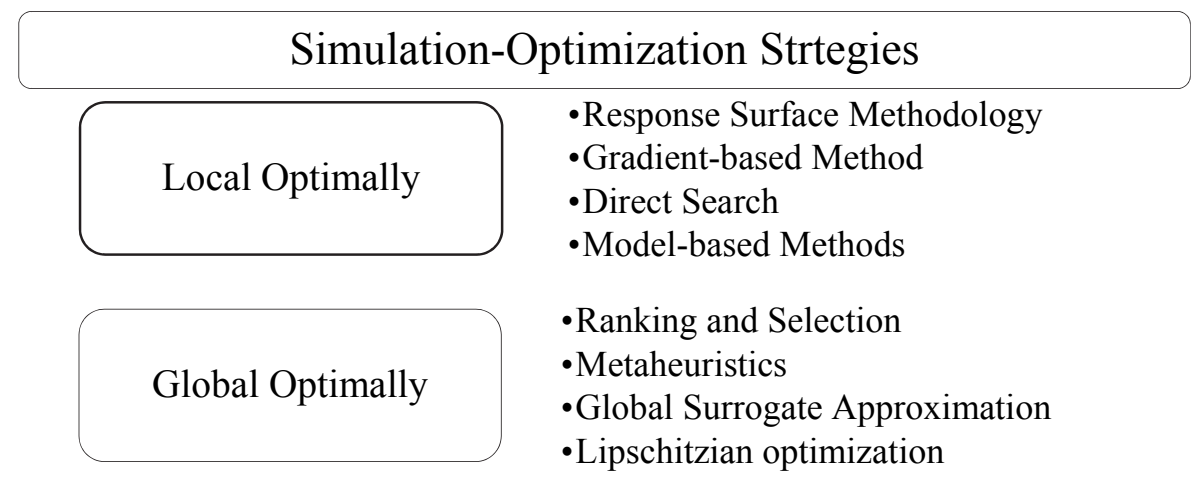

Fig. 6. Simulation optimization strategies based on locally and globally solution.

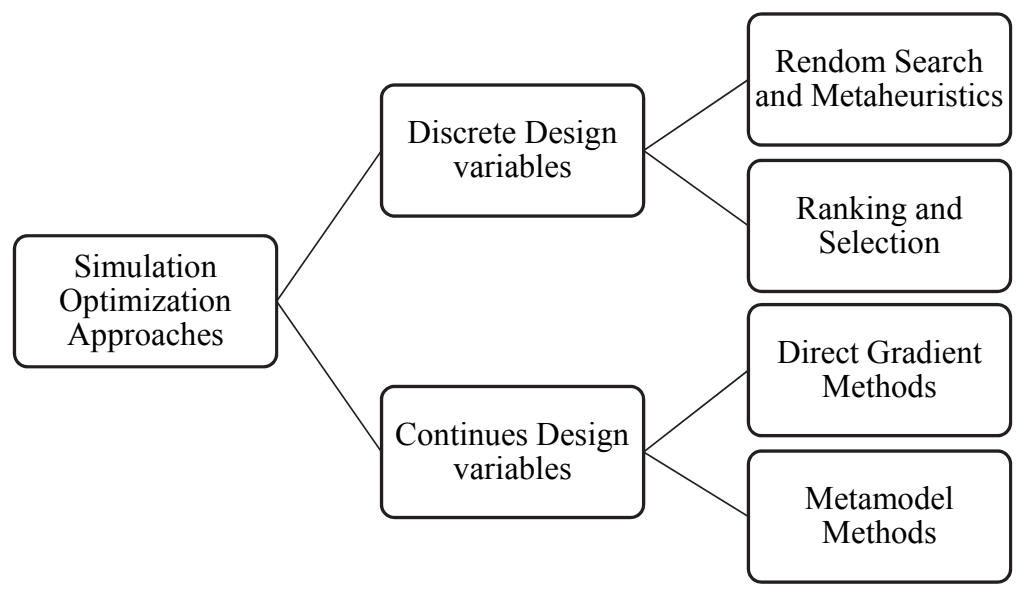

Fig. 7. Simulation optimization strategies based on nature of design variables.

\subsubsection{Applications of simulation-optimization}

Various types of problems in engineering design and management have been developed by application of different methods in SO (e.g. production, transportation and logistics, energy management, finance, engineering, and applied sciences). In a real case study, (Kleijnen, 1993) has applied SO methods in production planning to report practical decision support system in the Dutch company. In (Jin et al., 2001) the application of different metamodels have been studied (e.g. polynomial regression, multivariate adaptive regression splines, radial basis functions, and kriging) over 14 test SO problems in engineering design based on noisy or smooth behavior. In the other work by Kleijnen and Gaury (2003), four different techniques were combined: simulation, optimization, uncertainty analysis, and bootstrapping through implementing in a real case study in production control. The appropriate review study which addressed some applications of SO in sub-communities in machine learning problems, discrete event systems such as queues, operations, and networks, manufacturing, medicine and biology, 
engineering, computer science, electronics, transportation, and logistics have been done by Amaran et al. (2016).

Table 6

Application of SO (surrogate-based) in different engineering design and management problems

\begin{tabular}{|c|c|c|c|}
\hline ID & Application & ID & Application \\
\hline R2 & $\begin{array}{l}\text { Aerospace engineering (design of an aerospike } \\
\text { nozzle). }\end{array}$ & R33 & Semiconductor wafer fabrication system \\
\hline R3 & $\begin{array}{l}14 \text { test problems in engineering design based on } \\
\text { noisy or smooth behavior. }\end{array}$ & R34 & Discrete-event simulation $(\mathrm{M} / \mathrm{M} / 1)$ \\
\hline R4 & $\begin{array}{l}\text { Production Planning (Four station production } \\
\text { flow line) }\end{array}$ & R35 & $\begin{array}{l}\text { Wind farm power generation, product platform planning } \\
\text { (for universal electric motors), three-pane window heat } \\
\text { transfer, onshore wind farm cost estimation }\end{array}$ \\
\hline R5 & Production Planning (Kanban system) & R36 & Inventory Management \\
\hline R6 & Supply Chain Management & R38 & Nonpoint source pollution control \\
\hline R7 & Beam design problem & R39 & $\begin{array}{l}\text { Groundwater management (groundwater joint planning } \\
\text { process) }\end{array}$ \\
\hline $\mathrm{R} 8$ & The two-bar structure & $\mathrm{R} 40$ & $\begin{array}{l}\text { Thermodynamics (modeling of steam density as a function } \\
\text { of heat duty in a flash drum modeled) }\end{array}$ \\
\hline R9 & $\begin{array}{l}\text { Electrical engineering, chemical engineering, } \\
\text { mechanical engineering, and dynamic } \\
\text { programming }\end{array}$ & R42 & $\begin{array}{l}\text { manufacturing system (job shop consisting of four } \\
\text { machines and three buffers (or queues), }\end{array}$ \\
\hline $\mathrm{R} 10$ & A single server queueing, $\mathrm{M} / \mathrm{M} / 1$ hyperbola, & $\mathrm{R} 43$ & Inventory Management \\
\hline $\mathrm{R} 15$ & Network routing example & R44 & Inventory management \\
\hline R16 & Flyer plate experiments & R45 & $\begin{array}{l}\text { Skyhook dampers for the suspension of a half-car } \\
\text { nonlinear model driving on a rough road. }\end{array}$ \\
\hline $\mathrm{R} 17$ & $\begin{array}{l}\text { Review different application of simulation } \\
\text { optimization in engineering design and } \\
\text { management. }\end{array}$ & R46 & Schelling's segregation model \\
\hline $\mathrm{R} 18$ & 10-bar truss under varying loads & R47 & $\begin{array}{l}\text { Groundwater management (injection bore field design } \\
\text { problem) }\end{array}$ \\
\hline R19 & Design of two parts of the TV tube & R49 & $\begin{array}{l}\text { Production planning in manufacturing system (a scaled- } \\
\text { down semiconductor wafer fabrication system) }\end{array}$ \\
\hline $\mathrm{R} 20$ & $\begin{array}{l}\text { Expected steady-state waiting time of the } \\
\mathrm{M} / \mathrm{M} / 1 \text { queuing model, and the mean costs of a } \\
\text { terminating (s, S) inventory simulation }\end{array}$ & $\mathrm{R} 50$ & Design of a chemical cyclone, Manufacturing processes \\
\hline $\mathrm{R} 21$ & Inventory Management & R52 & $\begin{array}{l}\text { Steady two-way coupled hydro-elastic system, Racing } \\
\text { sailboat keel fin }\end{array}$ \\
\hline $\mathrm{R} 23$ & $\begin{array}{l}\text { A slat track, structural component of an aircraft } \\
\text { wing }\end{array}$ & R53 & $(\mathrm{s}, \mathrm{S})$ inventory policy \\
\hline $\mathrm{R} 24$ & Supply-chain management & R54 & $\begin{array}{l}\text { Well-known EOQ problem, the multi-item newsvendor } \\
\text { problem }\end{array}$ \\
\hline $\mathrm{R} 25$ & Compressed Natural Gas (CNG) engines & R55 & Compressor impellers for mass-market turbochargers are \\
\hline $\mathrm{R} 26$ & Inventory Management & R57 & $\begin{array}{l}\text { Soldier pile tieback anchor supported excavation in sandy } \\
\text { and gravelly site }\end{array}$ \\
\hline $\mathrm{R} 28$ & Inventory Management & R58 & Nonlinear Programming, pressure vessel design \\
\hline $\mathrm{R} 30$ & Job shop simulation problem & R59 & Metal forming processes, strip bending process \\
\hline $\mathrm{R} 32$ & Metal forming processes & R60 & $\begin{array}{l}\text { Skyhook control for the suspension of a half car model, } \\
\text { The dampers for a building exposed to earthquake } \\
\text { excitation }\end{array}$ \\
\hline
\end{tabular}


Recently, a work based on metamodel and Monte Carlo simulation method have been done by Li et al. (2016) applied in production planning of manufacturing system and compared with other approaches (e.g. mathematical programming). The application of robust design hybrid metamodeling in management science and engineering problems has been reviewed by Parnianifard et al. (2018). The application of SO in inventory management has been significantly interested in different studies such as Dellino et al. (2015, 2010a) and review papers (Jalali \& Van Nieuwenhuyse, 2015; Kleijnen, 2017). However, in this context among a review of the literature, the application of SO methods in different types of engineering design and management problems were considered and the results were represented in Table 6. Notable, we just targeted SO methods based on surrogates and robust design optimization in black-box and expensive simulation models under uncertainty. For such cases, computer experiments are conducted as the main supplementary of metamodel based robust simulation optimization.

\subsection{Uncertainty management in SO via robust design optimization}

In practice, most engineering problems have been affected by different sources of variations. One of the main challenges of SO is to address uncertainty in the model, by a variety of approaches, such as robust optimization, stochastic programming, random dynamic programming, and fuzzy programming. Uncertainty is undeniable which affect on the accuracy of simulation results while making variability on them. Under uncertain condition, robust SO allows us to define the optimal set point for input variables while keeping the output as more close as possible to ideal point, also with at least variation. Robust design approaches try to make processes insensitive to uncertainty as sources of variation by investigating qualified levels of design input factors. The source of variation in output can be divided into two main types, first is the variation due to variability in environmental (uncontrollable or noise) variables (Park \& Antony, 2008; Phadke, 1989), and second is the fluctuating of input (design) variables in their tolerance range (Anderson et al., 2015; Myers et al., 2016).

\section{Table 7}

Applied different strategies in literature for management of uncertainty.

\begin{tabular}{|c|c|c|c|}
\hline ID & Uncertainty management strategy & ID & Uncertainty management strategy \\
\hline $\mathrm{R} 1$ & Taguchi Approach & R32 & Dual response \\
\hline R4 & Stochastic programming & R36 & Taguchi Approach, Crossed Arrays \\
\hline R5 & $\begin{array}{l}\text { Scenario Cases (combination of non-controllable } \\
\text { input values), risk analysis (RA) and Monte Carlo }\end{array}$ & R38 & Two-stage robust optimization \\
\hline $\mathrm{R} 8$ & Dual response methodology & R39 & Fuzzy Logic \\
\hline R9 & Taguchi robust design & R43 & Taguchi Approach-Crossed Arrays \\
\hline $\mathrm{R} 11$ & Minimax approach & R44 & $\begin{array}{l}\text { Mean-variance trade-off approach (Taguchi, Dual } \\
\text { Response Surface), Worst Case. }\end{array}$ \\
\hline $\mathrm{R} 12$ & $\begin{array}{l}\text { Cross-validation, Parametric bootstrapping, } \\
\text { distribution free bootstrapning. }\end{array}$ & R45 & Probability logic approach \\
\hline $\mathrm{R} 13$ & jackknifed variance & R47 & Stochastic Optimization \\
\hline $\mathrm{R} 16$ & $\begin{array}{l}\text { Calibration of simulation model, trade-offs among } \\
\text { parameters }\end{array}$ & $\mathrm{R} 48$ & Squared Loss Function \\
\hline $\mathrm{R} 17$ & Robust Design & R50 & Expected quality loss \\
\hline $\mathrm{R} 18$ & $\begin{array}{l}\text { Taguchi quality loss, Minimax principle, Bayes } \\
\text { principle, }\end{array}$ & R51 & Expected Improvement (EI) \\
\hline R19 & Robust counterpart methodology & R52 & Stochastic programming \\
\hline $\mathrm{R} 21$ & Crossed array-Combined Array & R53 & Uncertainty on parameters distribution \\
\hline $\mathrm{R} 23$ & Robust design (dual response surface) & R54 & Minimax problem, Chance constraint definition \\
\hline $\mathrm{R} 24$ & Signal to Noise Ratio & R55 & Stochastic optimization algorithm \\
\hline $\mathrm{R} 26$ & Taguchi Approach-Crossed Arrays & R56 & Taguchi worldview \\
\hline $\mathrm{R} 27$ & Taguchi Approach-Crossed Arrays & R57 & Robust geotechnical design \\
\hline $\mathrm{R} 28$ & Taguchi Approach-Crossed Arrays & R58 & $\begin{array}{l}\text { Robust optimization based on the reverse model } \\
\text { (RMRO), Genetic Algorithms }\end{array}$ \\
\hline $\mathrm{R} 30$ & $\begin{array}{l}\text { Robustness is defined as the standard deviation of } \\
\text { one method's error values across different problems. }\end{array}$ & R59 & Leave-One-Out Cross-Validation \\
\hline R31 & Taguchi robust optimization & R60 & Stochastic approach \\
\hline
\end{tabular}


Robust design optimization is an engineering methodology to improve the performance of a model by minimizing the effects of variation without eliminating the causes since they are too difficult or too expensive to control. Robust simulation-optimization is about solving simulation model with uncertain data in a computationally tractable way. The main goal of robustness strategy is to investigate the best level of input factors setting for obtaining desirable output goal which is insensitive to the changeability of uncertain parameters. Tabl 7 illustrates different number of strategies which have been done in reviewed literature through the management of uncertainty in SO. Most of the times, in robust design approach the output goal is to gain the minimum distance of mean with target point and with at least variance, simultaneously. The main attention behind overall viewpoint via robust design method for design and development processes and products is concentrated on three aspects:

i. At least sensitivity to uncontrollable environmental conditions and robustness to any source of variation.

ii. Minimization of variability in product or process characteristics

iii. Minimizing deviance between the performance of product or process and its relevant target point.

\subsubsection{Robust optimization in the class of dual response}

The dual response surface approach has been successfully applied in robust process optimization. Jalali and Van Nieuwenhuyse (2015) have reviewed some methods of robust design optimization in the class of dual response which applied in simulation optimization, and concluded that the dual response surface approach is more attended among other techniques in that subject. This model has employed two metamodels separately for the process mean and another for the process variance. By combining both types of factors in process included design and noise (uncertain) variables, we can approximate the $y=$ $f(X, Z)$ as a function of design factors $(X)$ and uncertain factors $(Z)$. Due to the stochastic nature of the simulation model, repeated runs of the simulation model with the same combination of input variables, lead to different outputs. Typically, as the training set to improve the metamodel, the average magnitude of repeated runs can be used ( $\mathrm{Li}$ et al., 2010). If the stochastic simulation models is followed, each input combination $s,(s=1,2, \ldots, l)$ is repeated $m$ times $(r=1,2, \ldots, m)$, while in random simulation $m$ is the number of uncertainty scenarios. If $Y=\left(y_{1}, y_{2}, \cdots, y_{l}\right)$ is the $s$-dimensional vector with the simulation's output, then the mean and variance of each input combination can be computed by:

$$
\begin{aligned}
& \overline{y_{s}}=\frac{\sum_{r=1}^{m} y_{s r}}{m} \quad(s=1,2, \ldots, l) \\
& \sigma_{y_{s}}^{2}=\frac{\sum_{r=1}^{m}\left(y_{s r}-\overline{y_{s}}\right)}{m-1} \quad(s=1,2, \ldots, l)
\end{aligned}
$$

Note that in deterministic simulation models, In Eq. (1) and Eq. (2) we have $m=1$, for more information intereste readers can see (Dellino et al., 2015; Kleijnen, 2009b, 2015). For both Eq.(1) and Eq. (2) we assume that all scenario of uncertainties have the same probability, else based on probability of uncertainty in a model, equations for computing mean and variance can be rewritten as below:

$$
\begin{aligned}
& \overline{y_{s}}=\sum_{r=1}^{m} p\left(z_{r}\right) \cdot y_{s r} \quad, \text { for } \quad(s=1,2, \ldots, l) \\
& \sigma_{y_{s}}^{2}=\sum_{r=1}^{m} p\left(z_{r}\right) \cdot y_{s r}^{2}+\left(\sum_{r=1}^{m} p\left(z_{r}\right) \cdot y_{s r}\right)^{2} \quad(s=1,2, \ldots, l)
\end{aligned}
$$


where $p_{r}(z)$ denotes the probability of $r^{t h}$ scenario of uncertainty. Furthermore, there are different optimization approaches available on dual response methodology where some of them are referenced in (Ardakani \& Noorossana, 2008; Beyer \& Sendhoff, 2007; Nha et al., 2013; Yanikoglu et al., 2016), so here just for instance some most common robust optimization methods in class of dual response surface are mentioned:

Bi-objective model (Chen et al., 1999):

$$
\operatorname{Min}:\left[\frac{\overline{y_{s}}}{{\overline{y_{s}}}^{*}}, \frac{\sigma_{y_{s}}^{2}}{\sigma_{y_{s}}^{2}}\right]
$$

MSE (expected loss) model (Del Castillo \& Montgomery, 1993; Phadke, 1989):

$$
\operatorname{Min}:\left(\overline{y_{s}}-T\right)^{2}+\sigma_{y_{s}}^{2}
$$

Relaxing the "mean at target" constraint (Yanikoglu et al., 2016):

$$
\text { Min: } \sigma_{y_{s}}^{2} \text { s.t. } \overline{y_{s}} \leq T
$$

Weighted metric method (Ardakani \& Noorossana, 2008; Ardakani et al., 2009):

$$
\text { Min: } L p=\left[w\left(\frac{\hat{\sigma}_{y_{s}}-\sigma_{y_{s}}^{\min }}{\sigma_{y_{s}}^{\max }-\sigma_{y_{s}}^{\min }}\right)^{p}+(1-w)\left(\frac{{\overline{y_{s}}}-{\overline{y_{s}}}^{\text {min }}}{{\overline{y_{s}}}^{\text {max }}-{\overline{y_{s}}}^{\min }}\right)^{p}\right]^{\frac{1}{p}}
$$

where $0 \leq L p \leq 1$, and $p,(0 \leq p \leq \infty)$ denotes the importance of deviation for each objective function from its relevant utopia. The quantity $w$ illustrates the importance of the mean compared to the standard deviation.

Relaxing the "variance at target"(Lehman et al., 2004):

$$
\text { Min: } \overline{y_{s}} \text { s.t. } \sigma_{y_{s}}^{2} \leq T
$$

The standard deviation of the goal output (Dellino et al., 2015):

$$
\text { Min: } \overline{y_{s}} \text { s.t. } \sigma(y) \leq T
$$

When the probability distribution of noise (uncertain) parameters are unknown but historical data are available, some methods such as $\varphi$-divergence approach can be used to find the estimation of probability distribution (Moghaddam \& Mahlooji, 2016). Attending the probability of occurrence of uncertain parameters guide to tighter uncertainty set and less conservative robust solution. Yanikoglu et al. (2016) have suggested robust optimization in the class of dual response for such a problem when the probability distribution of uncertain parameters is unknown, but historical data are available:

$$
\operatorname{Min}_{S} \operatorname{Max}_{p(z)} \sigma_{y_{s p(z)}}^{2} \text { s.t. } \quad{\overline{y_{s}}}_{p(z)} \leq T, \quad \forall s \in S, \forall p(z) \in U
$$

where $p(z)$ represents the unknown true probability distribution of uncertain parameter $(z)$, and denotes a family of distribution that is obtained from old data $(\varphi$-divergence measure). Fig. 8 summarizes the strategies on facing with unknown probability of uncertain parameters. 


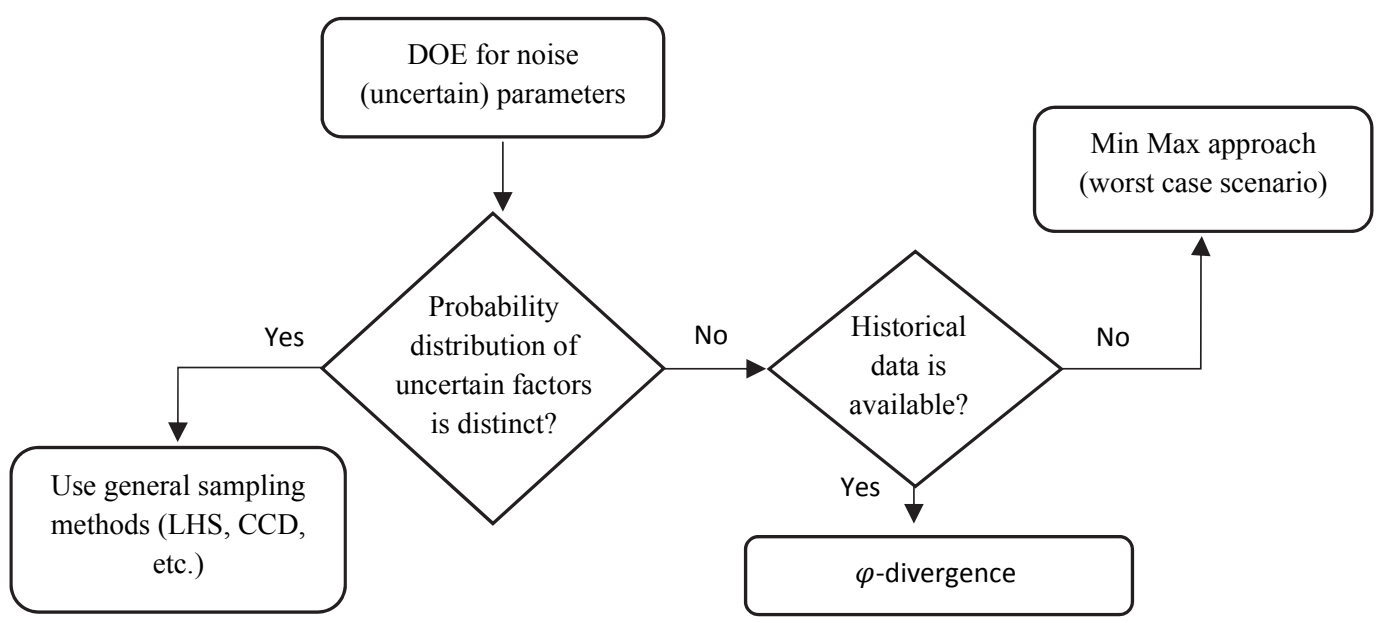

Fig. 8. The strategies in faced with unknown probability distribution of uncertain variables.

\subsection{Designing of computer experiments}

In this context, we focus on experiments via computers in simulation terms. Recently, the acronym of Design and Analysis of Simulation Experiments (DASE) has been introduced which is inspired of the common acronym in deterministic simulation as Design and Analysis of Computer Experiments (DACE) (Kleijnen, 2015). In practice, most simulation models have many combinations of input factors to run which may lead to time consuming and expensive patterns, e.g. the model with 7 input factors and 10 levels per each input requires $10^{7}$ combinations. In addition, in an uncertain environment, the analyzing of uncertain (noise) factors needs extra computational efforts. Furthermore, if we wish to analyze all combinations to investigate the best set of input factors, then we need extremely long simulation runs unless the appropriate sampling methods are successfully used. As to the number of sample points to produce an accurate response surface model, using $1.5 n$ to $2.5 n$ sample points have been recommended in literature, see, (Giunta et al., 1994; Simpson, Mauery et al., 2001) when $n$ is number of coefficients that need to be estimated.

\section{Table 8}

Different strategies of DOE for SO in literature.

\begin{tabular}{ll}
\hline DOE Strategy & Article ID \\
\hline Monte-Carlo method, Random & R10, R49, R56, R3, R59, R53 \\
Orthogonal array & R2, R9, R16 \\
Central Composite Design (CCD) & R1, R9, R14, R31 \\
Space filling, Latin Hypercube & R1, R3, R5, R7, R8, R9, R10, R11, R14, R16, R17, R18, \\
Sampling (LHS) & R21, R22, R25, R26, R27, R28, R29, R30, R32, R35, \\
& R36. R40. R43. R45. R48. R54. R58. R59. R60 \\
Full and Fractional Factorial Designs, & R8, R9, R15, R17, R24, R31 \\
Optimal Designs & R13, R20, R40, R52, R60, R35 \\
Sequential design & R14, R17, R56 \\
\hline Plackett-Burman & \\
\hline
\end{tabular}


There are three common types of design based on aliasing main or interaction effects in a model. While the effect of one factor depends on the levels of one or more other factors, called two of more degree of interaction between factors. A resolution-III design indicates that main effects may be aliased with two factor interactions. A resolution-IV design indicates that the main effects may be aliased with threefactor interactions. Two-factor interactions may be aliased with other two-factor interactions. Resolution-V (or higher) assumes that main effects and two-factor interactions can adequately model the factors. Table 8 shows some DOE methods that have been used in literature to design experimental points through analyzing and improving different engineering design problems.

\subsubsection{Latin Hypercube Sampling (LHS)}

LHS was first introduced by McKay et al. (1979). It is a strategy to generate random sample points, while guarantee all portions of the design space is depicted. Generally, LHS is intended to develop results in SO (Kleijnen, 2015). LHS has been commonly defined for designing computer experiments based on space filling concept (Bartz-Beielstein et al., 2015; Del Castillo, 2007). In general, for $n$ input variables, $m$ sample points are produced randomly into $m$ intervals or scenarios (with equal probability). For the particular instance the LHS design for $m=4, n=2$ is shown in Fig. 9 .

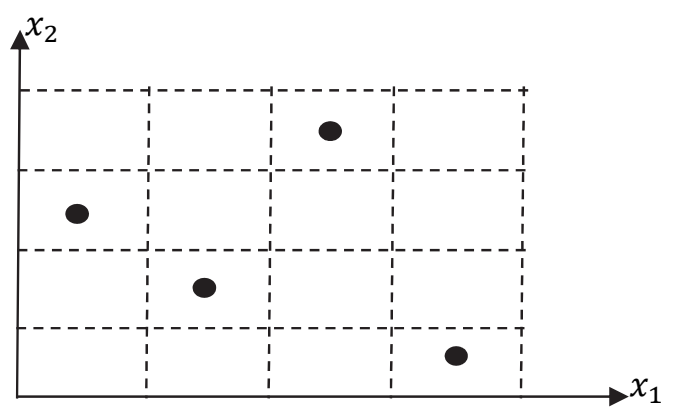

Fig. 9. An example for LHS design with two input factors, and four intervals

The LHS strategy proceeds as follows:

i. In LHS, each input range is divided into $m$ subranges (integer) with equal probability magnitudes, and numbered from 1 to $m$. In general, the number of $m$ is larger than total sample points in CCD (Kleijnen, 2004).

ii. In the second step, LHS place all $m$ intervals by random value between lower and upper bounds relevant to each interval, since each integers $1,2, \ldots, m$ appears exactly once in each row and each column of the design space. Note that, within each cell of design, the exact input value can be sampled by any distribution, e.g. uniform, Gaussian or etc.

Three common choices are available to ensure appropriate space filling of sample points in LHS design:

Minimax: This design tries to minimize the maximum distances in design space between any location for each design point and its nearest design points.

Maximin: This design attempts to maximize the minimum distance between any two design points.

Desired Correlational function: Inspired by Iman and Conover (1982) for the case of nonindependent multivariate input variables, the desired correlation matrix can be used to produce distribution free sample points in LHS. 


\subsubsection{Orthogonal Array (OA)}

The OA design can fill the whole design space like LHS, and it has strength to allocate points in each corner of design space (Owen, 1992). The OA was adapted to balance $\mathrm{n}$ discrete experimental factors in a continues space (Koehler \& Owen, 1996). The orthogonal array is matrix with $n$ rows and $p$ columns where $n$ is the number of experiments (input combination) and $p$ is the number of input factors. Each factor is divided into $m$ equal size ranges (grids), and sample points are allocated to these orthogonal grid spaces. In general, the orthogonal array is shown with symbol of $L_{n}\left(m^{p}\right)$, and has the following properties:

- For the input factor in any column, every level happens $n / m$ times.

- For the two input factors in any two columns, every combination of two levels happens $n / \mathrm{m}^{2}$ times.

- For the two factors in any two columns, all $n$ input combinations are combined by levels as belows:

$$
\{(1,1),(1,2), \cdots(1, m),(2,1),(2,2), \cdots,(2, m), \cdots,(m, 1),(m, 2), \cdots,(m, m)\}
$$

- By replacing any two columns of an orthogonal array, the remaining arrays are still orthogonal to each other.

- By removing one or some columns of an orthogonal array, the remaining arrays are orthogonal to each other, and OA is able to employ by a smaller number of factors.

\subsubsection{Sequential design}

Most time in practice due to expensive simulations (i.e. a single simulation run intensive time consuming), reducing the number of simulation runs (sample points) is interested. In mathematical statistics it is common that sequential designs are more well-organized than fixed sample size design (Wim et al., 2008). Different types of criteria can be used to sequentially define a candidate set of sample points, and most of them are based on mean squared prediction error (Van Beers \& Kleijnen, 2004). Kleijnen and Beers (2004) have proposed a customized sequential method based on crossvalidation and jackknifing approaches. In SO, Kleijnen (2017) has suggested replacing one-shot designs by sequential designs that are customized for the given simulation models. In other similar work, Wim et al. (2008) have employed bootstrapping technique to propose the sequential DOE with a smaller number of sample points than other alternative design like LHS, also with better results. A comparison on different sequential sampling approaches has been provided in (Jin, R. et al., 2002). Here, inspired by Kleijnen and Beers (2004) and Wim et al. (2008), the cross-validation and jackknifing method are followed due to four reasons. First, this method is adapted for expensive simulation models. Since this model is used the cross-validation method and does not need extra simulation runs, so it is appropriate for expensive simulation models. Second, evaluate I/O behavior with the highest estimated variance which is desirable in robustness study. Third, smaller prediction error than other sequential design (Van Beers \& Kleijnen, 2004). Fourth, this method is able to use for different types of metamodel such as polynomial regression and Kriging.

Following steps are shown the procedure of sequential design based on cross-validation and jackknifing:

- Expensive simulation runs are implemented for $n_{0}$ initial sample points, and the approximation metamodel is constructed based on initial result.

- Then select $c$ candidate points $(j=1,2, \ldots, c)$. To select candidate points we can use halfway spacefilling between vertices.

- To compare all candidates and select winner for expensive simulation, a jackknife variance for each candidate need to be computed separately and selected a point with maximum jackknife variance. 
To avoid extrapolating, we do not drop the sample points on vertices, $k$ sample on vertices is not droped, so $n_{0}$ is replaced by $n_{c}$ when $n_{c}=n_{0}-k$.

- Drop one point from model $-i,\left(i=1,2, \ldots, n_{c}\right)$ and construct metamodel based on $n_{0}-1$ remain points.

- Calculate the jackknife's pseudo-value for candidate $j$ as below:

$$
\tilde{y}_{j}^{-i}=n_{c} \times \hat{y}_{j}^{-0}-\left(n_{c}-1\right) \times \hat{y}_{j}^{-i} \quad \text { for } \quad i=1,2, \ldots, n_{c} \text { and } j=1,2, \ldots, c
$$

where $\hat{y}_{j}^{-0}$ is the original prediction for candidate $j$ with metamodel over initial sample points, and $\hat{y}_{j}^{-i}$ is prediction for candidate $j$ with metamodel over $n_{0}-i$ points (delete $i_{t h}$ sample point from $n_{0}$ set of points).

- The jackknife variance is computed for candidate $j$ by employing relevant pseudo-values:

$$
\widetilde{s_{J}^{2}}=\frac{1}{n_{c}\left(n_{c}-1\right)} \sum_{i=1}^{n_{c}}\left(\tilde{y}_{j}^{-i}-\overline{\widetilde{y}_{J}}\right)^{2} \quad \text { with } \quad \overline{\widetilde{y}}_{J}=\frac{1}{n_{c}} \sum_{i=1}^{n_{c}} \tilde{y}_{j}^{-i}
$$

where the candidate with maximum $\widetilde{s_{J}^{2}},\left(\arg \max _{j}\left\{\widetilde{s_{J}^{2}}\right\}\right)$ is a winner and is entered in a set of initial sample points after computing its relevant response with original simulation.

- All steps are repeated till stop creation is satisfied. Among literature we could not found any suggested appealing stopping criterion, see (Van Beers \& Kleijnen, 2004). It can be defined based on a limitation of computational time or cost.

\subsection{Metamodeling}

Metamodeling techniques have been used to avoid intensive computational and numerical simulation models, which might squander time and resource for estimating model's parameters. Metamodeling has utilized variety statistical and mathematical approach for interpreting parameters and their relationship in an original model. A metamodel or surrogate model by mathematical expression $\hat{Y}=f \overline{(X, Z)}$ can be replaced with true functional relationship $Y=f(X, Z)$, where $X$ and $Z$ denote respectively the design and the noise (uncertain) factors. The general overview of a metamodel with uncontrollable noise variables as uncertainty symbols is illustrated in (Fig. 10).

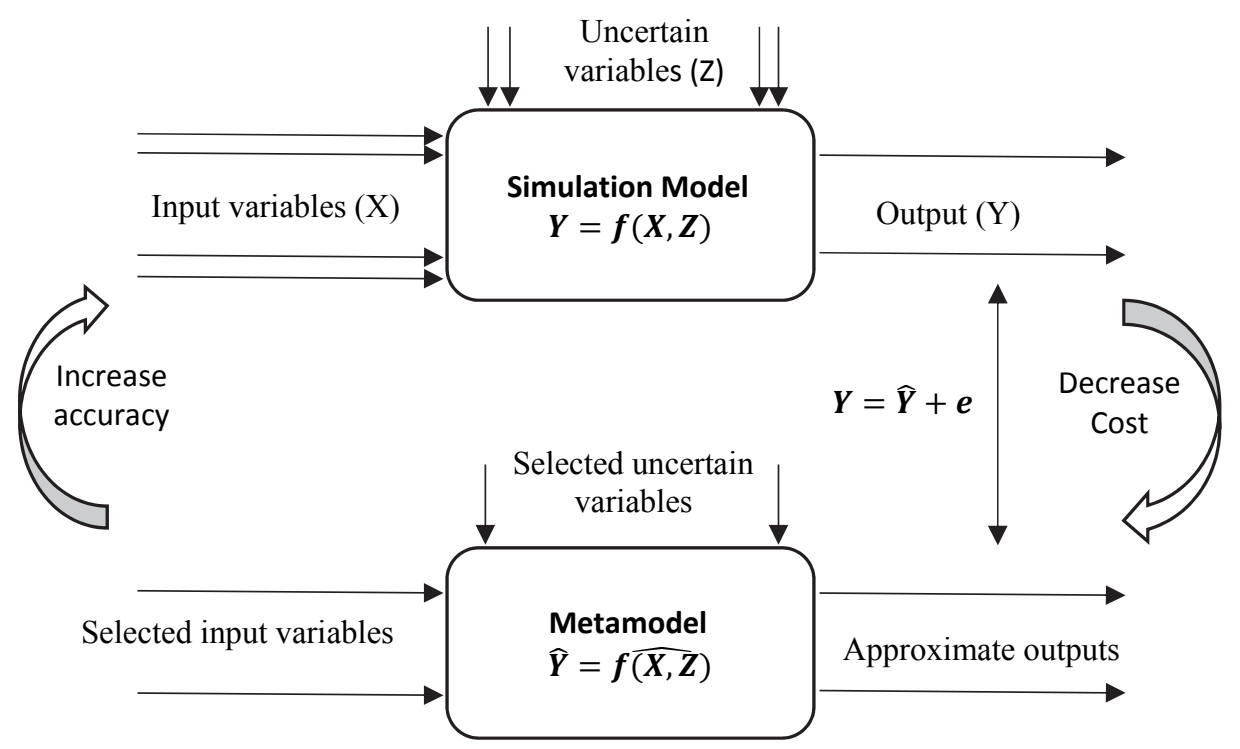

Fig. 10. The viewpoint of metamodel under uncertainty (noise variables) and relationship with a simulation model. 


\subsubsection{Polynomial regression}

Polynomial regression also called Response Surface Methodology (RSM) is a collection of statistical and mathematical techniques used for developing, improving, and optimizing the process. The functional applicability of RSM in literature can be i) approximate the relationship between design (dependent) variables and single or multi-response (independent variables), ii) investigating and determining the best operating condition for the process, by finding the best levels of design region which can satisfy operating limits, and iii) implementing robustness in the response(s) of the process by designing the process robust against uncertainty. Barton and Meckesheimer (2006) have claimed the RSM was successfully used in recent decades for processes with the stochastic application. Kleijnen (2017) has mentioned the RSM is sequential since it uses a sequence of local experiments and leads to the optimum input combination. He has also claimed that the RSM can achieve an appropriate track record in literature. Some of the initial applications of RSM in SO can be found in (Azadivar, 1999; Biles, 1974). Commonly, the main motivation of polynomial approximation for true response function is based on Taylor series expansion around a set of design points, see (Myers et al., 2016). The general overview of the first-order response surface model is shown as:

$$
y=f(X)=\hat{\beta}_{0}+\sum_{i=1}^{k} \hat{\beta}_{i} x_{i}+\varepsilon
$$

where $k$ is number of design variables. Most times, the curvature of response surface is stronger than the first model can approximate it even with the interaction terms, so a second-order model can be employed:

$$
y=f(X)=\hat{\beta}_{0}+\sum_{i=1}^{k} \hat{\beta}_{i} x_{i}+\sum_{i=1}^{k} \hat{\beta}_{i i} x_{i}^{2}+\sum_{i=1}^{k} \sum_{i<i^{\prime}=2}^{k} \hat{\beta}_{i i^{\prime}} x_{i} x_{i^{\prime}}+\varepsilon
$$

where $\widehat{\beta}_{0}, \hat{\beta}_{i}, \hat{\beta}_{i i}$ and $\hat{\beta}_{i i^{\prime}}$ are unknown regression coefficients and the term $\varepsilon$ is the usual random error (noise) component. The number of expression in a linear polynomial regression model is $p=k+1$, quadratic model is $p=\frac{1}{2}(k+1)(k+2)$, and cubic model is $p=\frac{1}{6}(k+1)(k+2)(k+3)$ when $n$ is number of input variables. By polynomial regression to fit reasonable metamodel, the sample size should be at least two or three times the number of expression ( $p$ ) (Jin et al., 2003).

\subsubsection{Kriging}

Since Daniel G. Krige (1951) addressed the geostatistics around six decades ago, today Kriging (also called Gaussian process) models have been used as a widespread global approximation technique (Jurecka, 2007). Kriging is an interpolation method which could cover deterministic data in a blackbox presentation, and it is highly flexible due to ability in employing a various range of correlation functions. In general, Kriging has been used in deterministic simulation models, i.e. Computer Aided Engineering (CAE). Kriging does not have many applications yet in random simulation (Kleijnen, 2005; Kleijnen, 2015). The higher accuracy of Kriging models than other alternatives such as polynomial regression is confirmed via different numerical cases in literature (Dellino et al., 2015; Jin et al., 2001; Simpson et al., 2001). In the Kriging model, a combination of a polynomial model and realization of a stationary point are assumed by the form of:

$$
y=f(X)+Z(X)+\varepsilon,
$$


$f(X)=\sum_{p=0}^{k} \hat{\beta}_{p} f_{p}(X)$

where the polynomial terms of $f_{p}(X)$ are typically first or second order response surface approach and coefficients $\widehat{\beta}_{p}$ are regression parameters $(p=0,1, \ldots, k)$. This types of Kriging approximation is called universal Kriging, while in ordinary Kriging instead of $f(X)$ the constant mean $\mu=E(y(x))$ is used. The term $\varepsilon$ describes approximation error, and the term $Z(X)$ represents realization of a stochastic process, which most time normally distributed Gaussian random process with zero mean, variance $\sigma^{2}$ and non-zero covariance. The correlation function of $Z(X)$ is defined by:

$$
\operatorname{Cov}\left[Z\left(x_{k}\right), Z\left(x_{j}\right)\right]=\sigma^{2} R\left(x_{k}, x_{j}\right)
$$

where $\sigma^{2}$ is process variance and $R\left(x_{k}, x_{j}\right)$ is the correlation function, and can be chosen from different functions which proposed in literature (e.g. exponential, Gaussian, linear, spherical, cubic, and spline). For instance, the general exponential correlation function is defined as below:

$$
R_{\theta, p}\left(x_{k}, x_{j}\right)=\prod_{i=1}^{n} \exp \left(-\theta_{i}\left|x_{k i}-x_{j i}\right|^{p_{i}}\right)
$$

where $n$ is dimension of input variables, and $p_{i}$ determines the smoothness of the correlation function and $\theta_{i}$ indicates the importance of $i^{\text {th }}$ input factor, while the higher $\theta_{i}$ denotes the less effect of factor $i$ on output. For $p_{i}=1$ and $p_{i}=2$ respectively the exponential and Gaussian correlation function is made.

\subsubsection{Validation of metamodel}

In general, to assess the predictor behavior and evaluating of the model, the techniques can be divided into two types based on the set of sampling points. The first type is the evaluated model by using training data (i.e. the set of data which is used in estimating model) and the second one is used for employing validating data (i.e. new set of data except for data which used in estimation). Some different methods have been suggested for evaluating a metamodel, while among them four more applicable validation methods are chosen to discuss in follow. Notably, mentioned methods are based on employing validation data in semi-expensive models, since in expensive simulation models impose extra computational costs due to extra simulation runs. Moreover, in such a case some methods such as cross-validation or bootstrapping can be used, see (Kleijnen, 2015).

\section{1- R-square Index}

This method can be used to compare first order against the second or above order polynomials regression, or RSM with other metamodels namely Kriging. The $R^{2}$ coefficient is defined as:

$$
R^{2}=1-\frac{\sum_{j=1}^{m}\left(y_{j}-\widehat{y}_{J}\right)^{2}}{\sum_{j=1}^{m}\left(y_{j}-\bar{y}_{J}\right)^{2}}=1-\frac{\text { Mean Square Error }}{\text { Variance }}
$$

where $\overline{y_{J}}$ is mean of observed values $\left(y_{j}\right)$ and $\widehat{y}_{J}$ is corresponding predicted values. 


\section{2- Adjusted R-square Index}

Due to the index $R^{2}$ always increases when the terms are added to the model, some regression analysts prefer to use another statistic index called adjusted $R$-square:

$$
R_{A d j}^{2}=1-\frac{n-1}{n-p}\left(1-R^{2}\right)
$$

By adding variables to the model, generally the statistic $R_{A d j}^{2}$ will not increase. In fact, the value of adjusted $R$-square often decreases, if unnecessary terms are added to the model.

\section{3- Relative Maximum Absolute Error (RMAE)}

While the larger magnitude of R-square indicates better overall accuracy, the smaller amount of RMAE indicates the smaller local error. A suitable overall accuracy does not necessarily signify a good local accuracy (Jin et al., 2003).

$$
R M A E=\frac{\max \left\{\left|y_{1}-\hat{y}_{1}\right|,\left|y_{2}-\hat{y}_{2}\right|, \ldots,\left|y_{m}-\hat{y}_{m}\right|\right\}}{\sqrt{\frac{1}{m} \sum_{j=1}^{m}\left(y_{j}-\widehat{y}_{J}\right)^{2}}} .
$$

\section{4- Cross-validation}

The cross validation method can be used when collecting new data or further information about simulation model is costly. The cross validation uses an existed data and does not require to re-run of the expensive simulation. This method is also called leave- $k$-out cross-validation to validate metamodel (i.e. in each run $k$ sample points would be removed from an initial training sample points)(Kleijnen, 2015). The leave-one-out cross validation $(k=1)$ is briefly explained next that is most popular than others:

Step 1: Delete $s^{\text {th }}$ input combination and relevant output from the complete set of $l$ combination $(s=$ $1,2, \ldots, l)$.

Step 2: Approximate the new model by employing $l-1$ remain rows $s_{-1}$.

Step 3: Predict output for left-out point $\left(s_{-1}\right)$ with metamodel which obtained from Step 2.

Step 4: Implement the preceding three previous steps for all input combination (sample points) and compute $n$ predictions $\left(\hat{y}_{s}\right)$.

Step 5: The prediction result can be compared with the associated output in original simulation model.

The total comparison can be done through a scatter plot or eyeball to decide whether or not metamodel is acceptable.

\subsection{Robust metamodeling in SO}

There are different number of methodologies in optimizing the deterministic simulation, but there are few number of studies have been done on random (stochastic) SO problems under uncertainty and the effect of noise parameters, particularly based on the combination of metamodels and robust optimization, see (Simpson, Poplinski et al., 2001) and two recent review papers by Amaran et al. (2016) and Kleijnen (2017). Table 9 depicts a different combination of SO methods which have been applied in reviewed articles. Barton (1992) has introduced the Taguchi methods as an alternative to metamodeling strategies. Bates et al. (2006) have shown that the Taguchi crossed array was more successful than the dual response designs in its relevant numerical example. Others (Dellino \& Meloni, 
2015; Kleijnen, 2015; Myers et al., 2016; Vining \& Myers, 1990) have combined the Taguchi approach with approximation methods to use the advantages of both methods. Fig. 11 illustrates a general procedure in SO method under uncertain condition based on surrogate models and Taguchi termonology (Dellino \& Meloni, 2015; Kleijnen, 2015).

Table 9

Simulation optimization methods applied in literature ("M" means multi-objective, "C" means constrained problem)

\begin{tabular}{llllll}
\hline ID & Type & Methodologies & ID & Type & Methodologies \\
\hline R1 & $\begin{array}{l}\text { RSM-Kriging-Neural Networks-Rule } \\
\text { Induction. }\end{array}$ & R31 & & $\begin{array}{l}\text { First-order and second-degree polynomials } \\
\text { (RSM) and Kriging. }\end{array}$ \\
R2 & M & $\begin{array}{l}\text { Kriging, Response Surface, simulated } \\
\text { annealing algorithm, generalized } \\
\text { reduced gradient (GRG). }\end{array}$ & R32 & C & $\begin{array}{l}\text { Deterministic Sequential Approximate } \\
\text { Optimization (SAO), finite element } \\
\text { method, and single response surface } \\
\text { modeling. }\end{array}$ \\
R3 & $\begin{array}{l}\text { Polynomial regression, multivariate } \\
\text { adaptive regression splines, radial basis } \\
\text { functions, and Kriging. }\end{array}$ & R33 & M & $\begin{array}{l}\text { Genetic algorithm, on-line and off-line } \\
\text { scheduler, and RSM. }\end{array}$ \\
R4 & Integer linear programming and RSM. & R34 & Monotonicity preserving Kriging models \\
and distribution-free bootstrapping.
\end{tabular}

$\begin{array}{llll}\text { R5 } \mathrm{M} / \mathrm{C} \quad \begin{array}{l}\text { Stochastic Optimization, the Genetic R35 } \\ \text { algorithm }(\mathrm{GA}), \quad \mathrm{RSM}, \text { and } \\ \text { bootstrapping. }\end{array} & \begin{array}{l}\text { Adaptive hybrid functions (combination of } \\ \text { quadratic response surface, radial basis } \\ \text { functions, and Kriging), and Cross } \\ \text { validation. }\end{array} \\ \text { R6 C } & \begin{array}{l}\text { Genetic Algorithm and Mixed Integer } \\ \text { Programming. }\end{array}\end{array}$

$\begin{array}{llllll}\text { R7 C } & \begin{array}{l}\text { (Adaptive)Response Surface Method, } \\ \text { and Simulated annealing global } \\ \text { optimization method. }\end{array} & \text { R37 } & \begin{array}{l}\text { Select and review 10 top articles in } \\ \text { simulation optimization. }\end{array} \\ \text { R8 } & \text { C } & \begin{array}{l}\text { Polynomial regression, Kriging, and } \\ \text { Radial Basis Functions (RBF). }\end{array} & \text { R38 } & \text { C } & \begin{array}{l}\text { Hydrologic simulation and Mathematical } \\ \text { Programing. }\end{array}\end{array}$

$\begin{array}{lllll}\text { R9 } & \begin{array}{l}\text { RSM, Kriging, regression splines, } \\ \text { regression trees, and neural networks. }\end{array} & \text { R39 C } & \text { RSM and fuzzy linear programming. } \\ & \text { Ordinary Kriging and }\end{array}$

R10 Ordinary Kriging and classic cross R40 Integer programming formulation, low-
validation. complexity surrogate model, machine learning techniques, derivative based or algebraic solvers, reduced-order modeling, and error maximization sampling (EMS).

\begin{tabular}{|c|c|c|c|}
\hline $\mathrm{R} 11$ & $\begin{array}{l}\text { Updated correlation parameter } \\
\text { estimates. }\end{array}$ & R41 & $\begin{array}{l}\text { Multiple surrogates techniques } \\
\text { (polynomial regression and Kriging). }\end{array}$ \\
\hline $\mathrm{R} 12$ & Low order polynomial and Kriging. & $\mathrm{R} 42$ & $\begin{array}{l}\text { Statistical Selection Methods (SSM), } \\
\text { Metaheuristics (MH), Memory-based } \\
\text { Metaheuristics (MMH), Random Search } \\
\text { (RS), Stochastic Approximation (SA), } \\
\text { Sample Path Optimization (SPO) and } \\
\text { Metamodel-based Methods, Gradient } \\
\text { Surface Methods (GSM), Surrogate } \\
\text { Management Framework (SMF), Reverse } \\
\text { Simulation Technique (RST), } \\
\text { Retrospective Simulation Response }\end{array}$ \\
\hline $\mathrm{R} 13$ & $\begin{array}{l}\text { Kriging, cross-validation, and } \\
\text { jackknifing. }\end{array}$ & $\mathrm{R} 43$ & RSM and Kriging \\
\hline R14 & $\begin{array}{l}\text { Polynomial regression, Kriging, and } \\
\text { cross-validation. }\end{array}$ & $\mathrm{R} 44 \mathrm{M} / \mathrm{C}$ & RSM, Kriging, and neutral network. \\
\hline R15 & $\begin{array}{l}\text { RSM, regression spline, spatial } \\
\text { correlation (Kriging), radial basis } \\
\text { function, and neural network. }\end{array}$ & R45 & $\begin{array}{l}\text { Kriging metamodel and Monte Carlo } \\
\text { simulation. }\end{array}$ \\
\hline
\end{tabular}




\section{Table 9}

Simulation optimization methods applied in literature ("M" means multi-objective, "C" means constrained problem) (Continued)

\begin{tabular}{|c|c|c|c|c|c|}
\hline $\mathrm{R} 16$ & & $\begin{array}{l}\text { The Bayesian approach, Gaussian } \\
\text { process based emulator, free surface } \\
\text { velocity, and third-degree polynomial } \\
\text { response surface. }\end{array}$ & R46 & & $\begin{array}{l}\text { Bayesian inference and Interval } \\
\text { metamodel. }\end{array}$ \\
\hline $\mathrm{R} 17$ & $\mathrm{M} / \mathrm{C}$ & $\begin{array}{l}\text { Polynomial functions, Kriging, neural } \\
\text { networks, Radial Basis Functions } \\
\text { (RBF), Multivariate Adaptive } \\
\text { Regression Splines (MARS), least } \\
\text { interpolating polynomials, and } \\
\text { inductive learning. }\end{array}$ & R47 & $\mathrm{M} / \mathrm{C}$ & Monte-Carlo Simulation. \\
\hline $\mathrm{R} 18$ & $\mathrm{C}$ & $\begin{array}{l}\text { Kriging (spatial correlation } \\
\text { metamodels) and generalized expected } \\
\text { improvement criterion. }\end{array}$ & $\mathrm{R} 48$ & & $\begin{array}{l}\text { RSM, gradient-based methods, discrete } \\
\text { optimization via simulation, sample path } \\
\text { optimization, direct search methods, } \\
\text { random search methods, and model-based } \\
\text { methods. }\end{array}$ \\
\hline R19 & & RSM and Kriging. & R49 & M & $\begin{array}{l}\text { Transfer function modeling and time-series } \\
\text { pre-specified by forecasting methods. }\end{array}$ \\
\hline $\mathrm{R} 20$ & & Kriging and bootstrapping. & $\mathrm{R} 50$ & M & $\begin{array}{l}\text { A Gaussian process metamodel, Monotone } \\
\text { cubic spline, and computer-aided IPTD } \\
\text { (Integrated Parameter and Tolerance } \\
\text { Design) approach. }\end{array}$ \\
\hline $\mathrm{R} 21$ & & RSM and Kriging. & R51 & & $\begin{array}{l}\text { Gaussian process or Kriging surrogates, } \\
\text { global optimization algorithm, surrogate- } \\
\text { based algorithms, nature-inspired } \\
\text { algorithms, and evolutionary algorithms. }\end{array}$ \\
\hline $\mathrm{R} 22$ & & $\begin{array}{l}\text { Kriging, classic linear regression } \\
\text { (RSM), and bootstrapping. }\end{array}$ & R52 & & $\begin{array}{l}\text { A quasi Monte Carlo (MC) simulation, } \\
\text { deterministic multi-resolution lattice } \\
\text { points, thin plate spline (TPS) metamodel } \\
\text { (which is a special case of RBF), and } \\
\text { swarm optimization. }\end{array}$ \\
\hline $\mathrm{R} 23$ & & $\begin{array}{l}\text { RSM, Monte-Carlo simulations, and } \\
\text { finite element design. }\end{array}$ & R53 & & Regression models (RSM). \\
\hline $\mathrm{R} 24$ & & Sequential Bifurcation (SB) & R54 & & $\varphi$ - divergence and Kriging \\
\hline $\mathrm{R} 25$ & $\mathrm{M} / \mathrm{C}$ & $\begin{array}{l}\text { Kriging, evolutionary optimization } \\
\text { algorithms (EAs), Data Envelopment } \\
\text { Analysis (DEA), adopted optimization } \\
\text { system, and Non-dominated Sorting } \\
\text { Genetic Algorithm-II (NSGA-II). }\end{array}$ & R55 & M & $\begin{array}{l}\text { Polynomial response surface, Kriging, } \\
\text { computational fluid dynamics (CFDs) } \\
\text { solver, and Monte Carlo simulation. }\end{array}$ \\
\hline $\mathrm{R} 26$ & & RSM & R56 & M & Polynomial regression and Kriging. \\
\hline $\mathrm{R} 27$ & & Kriging & R57 & M & $\begin{array}{l}\begin{array}{l}\text { Quasi-response surface } \\
\text { gradient-based robustness }\end{array} \begin{array}{c}\text { approach, } \\
\text { measure, }\end{array} \\
\text { minimum distance (MD) algorithm, and } \\
\text { weighted sensitivity index. }\end{array}$ \\
\hline $\mathrm{R} 28$ & & $\begin{array}{l}\text { RSM, one layer Kriging, and two layers } \\
\text { Kriging }\end{array}$ & R58 & $\mathrm{C}$ & $\begin{array}{l}\text { Kriging, single-loop optimization } \\
\text { structure. }\end{array}$ \\
\hline R29 & & Kriging & R59 & $\mathrm{C}$ & $\begin{array}{l}\text { Radial basis function, leave-one-out cross- } \\
\text { validation, and sequential improvement } \\
\text { criterion }\end{array}$ \\
\hline $\mathrm{R} 30$ & $\mathrm{C}$ & $\begin{array}{l}\text { Multivariate adaptive regression } \\
\text { splines, Kriging, RBF, Artificial Neural } \\
\text { Networks, and Support Vector } \\
\text { Regression. }\end{array}$ & R60 & & $\begin{array}{l}\text { Monte Carlo, kriging, sequential } \\
\text { approximate optimization (SAO), and } \\
\text { gradient realization. }\end{array}$ \\
\hline
\end{tabular}




\subsubsection{Bootstrapping}

Consequently both sensitivity analysis and optimization must be performed based on metamodels to interpret the observed simulation input/output data (Van Beers \& Kleijnen, 2004). Sensitivity analysis can serve optimization of the simulated system (Kleijnen, 2010). The sensitivity analysis is based on a fixed condition for a system just with the variation of one factor.

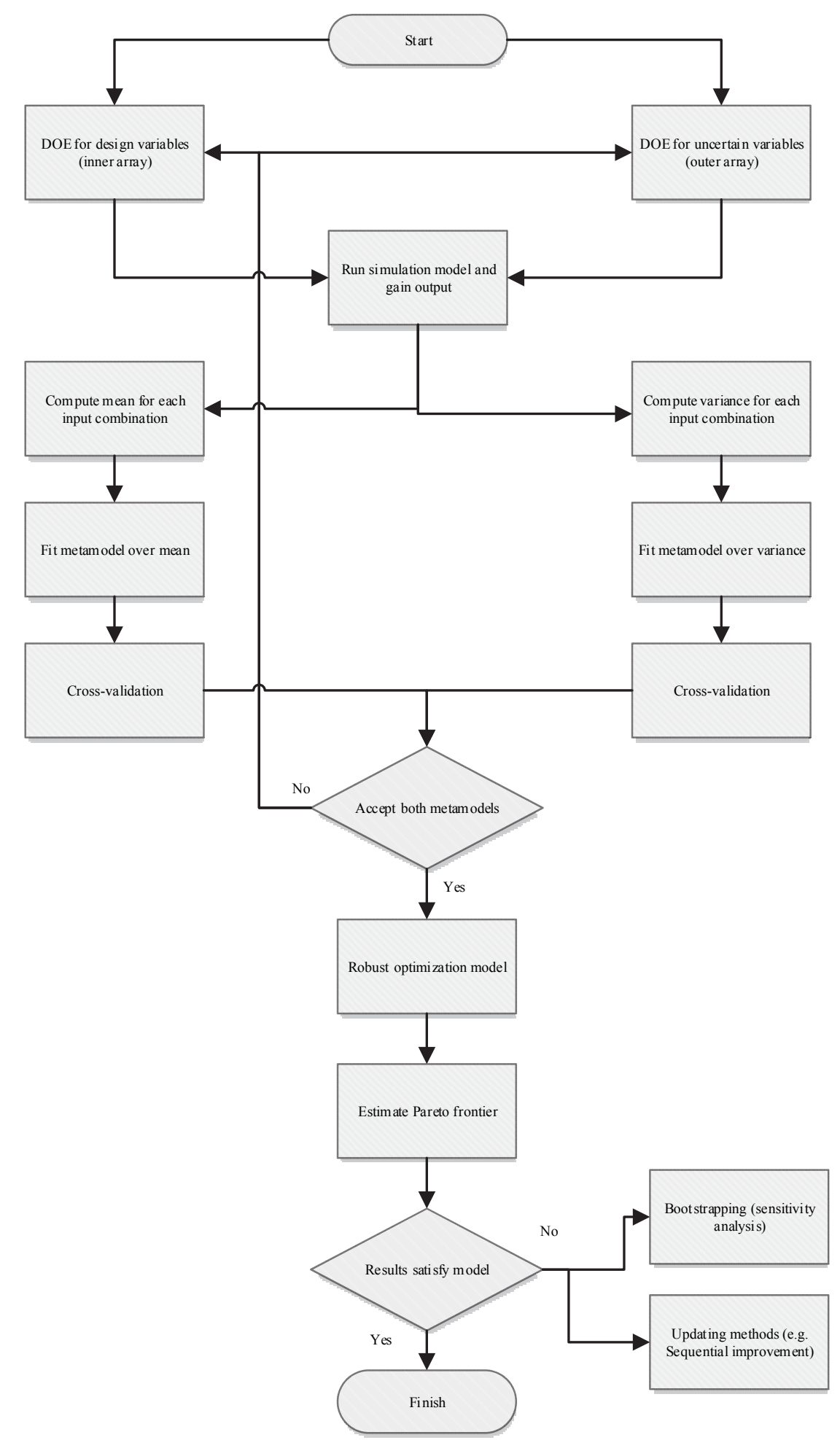

Fig. 11. Main steps in MBRSO procedure 
Kleijnen (2009b) has recommended that the designs for sensitivity analysis and optimization need to be combined for the robust optimization. The parametric bootstrapping has been suggested in such a case while we assume a specific distribution type is estimated from I/O simulation data on hand. The basics of this method have been explained in (Kleijnen, 2004; Kleijnen, 2010; Kleijnen, 2009b, 2015). In stochastic simulation, each input combination $X$ is replicated a number of times $m \geq 1$. In an expensive simulation, yet just the number of replication are less, so good results cannot be expected to gain by this types of bootstrapping (i.e. rarely can find the exact distribution of I/O simulation data). Moreover, a simple method for estimating the exact variance of predictor is distribution-free bootstrapping, see (Dellino \& Meloni, 2015).

\subsubsection{Sequential improvement}

The sequential improvement methods have been interested in engineering design problems to a tradeoff between local and global search with the criterion of expected improvement. Abspoel et al. (2001) have proposed a sequential approximate approach to solve $\mathrm{SO}$ with integer design variables. Sequential improvement can be appropriately used in different practical engineering design problems, (e.g. Wiebenga et al., 2012; Havinga et al., 2017) in improving metal forming processes, (Jurecka et al., 2007) in the 10-bar truss under varying loads, and (Zhang, J et al., 2017) for optimal design of the skyhook control for the suspension of a half-car model. These methods are combined with two main parts, first statistical part consists of DOE and metamodeling techniques, and second evolutionary algorithms. Note that, this method handles capturing the behavior of the overall design space, so the global approximation methods (e.g. Kriging) can be covered by this method while polynomial regression cannot, due to locally behavior. Sometimes due to the low correlation between predicted optimum point (which estimated by metamodel) and other points, the metamodel does not show enough accuracy in optimal point compared with the original model, for more information see (Havinga et al., 2017; Jurecka, F et al., 2007; Sóbester et al., 2004).

\section{Discussion and results}

Polynomial regression metamodel can be established by two main consecutive steps, screening and optimization. In the screening step, the significant interested levels of input factors can be identified, so in the second step, the closer interval of input factors can be studied (Kleijnen, 2010; Myers et al., 2016). Haftka et al. (2016) have considered the latest development on global-local approach. In this approach, the rough surrogate model is constructed in entire design space, and then apply it to zoom on promising regions. Wang, (2003) has developed the adaptive RSM which instead of regions with largescale, made a new DOE through the central composite design or LHS in reduced region (See Peri \& Tinti, 2012). On the contrary, a polynomial model is easy to establish, more distinct in the sensitivity analysis, and cheap to work (Wang \& Shan, 2007). In addition, comparison of different metamodel types such as polynomial regression and Kriging in practical problems also remains a challenging topic (Beers \& Kleijnen, 2004; Kleijnen, 2017; Wang \& Shan, 2007). More support is currently available for the implementation of polynomial regression with computer software than other types of metamodels (e.g. Design Expert (V. 10), Minitab (V. 17), SAS (V. 14.2), SPSS (V.23), and so on). For Kriging the MATLAB (DACE, free Kriging toolbox ${ }^{2}$ can be used (Lophaven et al., 2002). In addition, ARCGIS (geostatistical analysis) and Isatis (geographical analysis) can support the Kriging surrogate model, but the number of input factors does not exceed three (Kleijnen, 2009b).

However, a study in literature shows there is a lack of software package that can cover Kriging surrogate model in the framework of practical engineering design (Jin et al., 2001; Kleijnen, 2009b), while it has been more employed for academically usage than for practical problems in the real world (Jalali \& Van Nieuwenhuyse, 2015). Viana et al. (2014) have listed a number of existed commercial software (e.g. BOSS/Quattro, DAKOTA, HyperStudy, IOSO, LS-OPT, OPTIMUS, and VisualDOC) by highlighting their metamodeling and optimization capabilities, while they have claimed that for many these software

\footnotetext{
2. http://www2.imm.dtu.dk/pubdb/views/edocdownload.php/1460/zip/imm1460.zip
} 
systems, metamodeling is not a final goal. In practice, most problems can be supported by polynomial regression requirements, and due to less complexity, process designers have preferred to use it than other metamodels, (See Forsberg \& Nilsson, 2005; Jalali \& Van Nieuwenhuyse, 2015; Jin et al., 2003; Simpson et al., 2004). However, due to strength points of Kriging, recently there is a significant increasing trend to attend more in the application of common modern metamodel namely Kriging, compared to classical metamodel techniques such as the different order of polynomial regression. Kriging is a popular method for metamodeling with simulation data (Havinga et al., 2017). The Kriging gives more accurate and flexible approximation than polynomial regression due to fit globally over whole design space (Dellino, 2015; Jin et al., 2001; Simpson, Poplinski et al., 2001). The main advantages of Kriging over polynomial regression is exact interpolating of Kriging, i.e. the predicted values and simulated output in the set of observed input values are exactly equal (Kleijnen, 2005). In general, Kriging predicts poorly in the case of extrapolation outside observed sample data (Kleijnen \& Beers, 2004).

Most methods mentioned in this context just have been tested in theoretical settings of problems, so applying these methods in practical problems and in-depth comparing of their performance can be an interesting area for additional research (Dellino, 2009; Jalali \& Van Nieuwenhuyse, 2015). Kleijnen, (2009b) has emphasized on applying metamodels particularly Kriging in practical random simulation models, which are more complicated than the academic $\mathrm{M} / \mathrm{M} / 1$ queueing and (s, S) inventory models. Another shortcoming which has been revealed by reviewing literature is that most publications assume single variable output, whereas in practice simulation models have to be covered by multi-variable output methodology (Kleijnen, 2009b; Simpson, Mauery et al., 2001; Teleb \& Azadivar, 1994). Yet, investigating suitable DOE for multiple outputs has been an interesting topic for researchers (Kleijnen, 2005). To the best of our knowledge, rarely can we find any study which considers variability in design variables parallel with noise variables. Most studies consider the variability of environmental factors, so they have assumed that design variables can be exactly controlled in their relevant values, while in practice this assumption may not hold, see (He et al., 2010; Sanchez, 2000). Most of the times in practice important uncertainty can be toleranced in nominal value of design variables (Myers et al., 2016).

\section{Conclusion}

In this paper, the latest developments on optimization of complex simulation models under uncertainty have been investigated. Intensive attention was focused on surrogate based methods hybrid robust design optimization, particularly according to dual response methodology. These types of methods are classified as MBRSO. Main methodologies that have been used in the reviewed articles have been highlighted, while important methods were discussed. Outstanding shortcomings and also positive points of each method were mentioned based on discussed topics. Respect to advantages and disadvantages of both metamodels (polynomial regression and Kriging), appropriate methods which integrated both metamodels (hybrid surrogate methods) in practical problems have not been attended enough. The low-order polynomial can be used in screening and Kriging for optimizing as well. Proposing methodologies which can cover different gaps mentioned in discussion and result section can be interesting topics for future works by researchers.

\section{References}

Abspoel, S. J., Etman, L. F. P., Vervoort, J., van Rooij, R. a., a.J.G. Schoofs, \& Rooda, J. E. (2001). Simulation based optimization of stochastic systems with integer design variables by sequential multipoint linear approximation. Structural and Multidisciplinary Optimization, 22(2), 125-139.

Aghaei Chadegani, A., Salehi, H., Yunus, M. M., Farhadi, H., Fooladi, M., Farhadi, M., \& Ale Ebrahim, N. (2013). A comparison between two main academic literature collections: Web of Science and Scopus databases. Asian Social Science, 9(5).

Amaran, S., Sahinidis, N. V, Sharda, B., \& Bury, S. J. (2016). Simulation optimization: a review of algorithms and applications. Annals of Operations Research, 240(1), 351-380.

Anderson, R., Wei, Z., Cox, I., Moore, M., \& Kussener, F. (2015). Monte Carlo Simulation Experiments for 
Engineering Optimisation. Studies in Engineering and Technology, 2(1), 97-102.

Ardakani, M. K., \& Noorossana, R. (2008). A new optimization criterion for robust parameter design - The case of target is best. International Journal of Advanced Manufacturing Technology, 38(9), 851-859.

Ardakani, M. K., Noorossana, R., Akhavan Niaki, S. T., \& Lahijanian, H. (2009). Robust parameter design using the weighted metric method-the case of "the smaller the better." International Journal of Applied Mathematics and Computer Science, 19(1), 59-68.

Azadivar, F. (1999). Simulation optimization methodologies. In Proceedings of the 31st conference on Winter simulation: Simulation---a bridge to the future (pp. 93-100).

Banks, J., Nelson, B. L., Carson, J. S., \& Nicol, D. M. (2010). Discrete-Event System Simulation (Fifth Edition). Published by Pearson.

Barton, R. R. (1992). Metamodels for simulation input-output relations. Proceedings of the 24th Conference on Winter Simulation - WSC '92, (January), 289-299.

Barton, R. R., \& Meckesheimer, M. (2006). Metamodel-Based Simulation Optimization. In Handbooks in Operations Research and Management Science (Vol. 13, pp. 535-574).

Bartz-Beielstein, T., Jung, C., \& Zaefferer, M. (2015). Uncertainty Management Using Sequential Parameter Optimization. Uncertainty Management in Simulation-Optimization of Complex Systems, 59.

Bates, R. A., Kenett, R. S., Steinberg, D. M., \& Wynn, H. P. (2006). Robust Design Using Computer Experiments. Progress in Industrial Mathematics at ECMI, 8.

Beyer, H. G., \& Sendhoff, B. (2007). Robust optimization - A comprehensive survey. Computer Methods in Applied Mechanics and Engineering, 196(33), 3190-3218.

Biles, W. E. (1974). A gradient - regression search procedure for simulation experimentation. In Proceedings of the 7th conference on Winter simulation-Volume 2 (pp. 491-497). Winter Simulation Conference.

Carson, Y., \& Maria, A. (1997). Simulation Optimization: Methods and Applications. Proceedings of the 29th Conference on Winter Simulation (1997), 118-126.

Chang, X., Dong, M., \& Yang, D. (2013). Multi-objective real-time dispatching for integrated delivery in a Fab using GA based simulation optimization. Journal of Manufacturing Systems, 32(4), 741-751.

Chen, V. C. P., Tsui, K. L., Barton, R. R., \& Allen, J. K. (2003). A review of design and modeling in computer experiments. Statistics in Industry, 22, 231-261.

Chen, W., Wiecek, M. M., \& Zhang, J. (1999). Quality utility : a Compromise Programming approach to robust design. Journal of Mechanical Design, 121(2), 179-187.

Cozad, A., Sahinidis, N. V, \& Miller, D. C. (2014). Learning surrogate models for simulation-based optimization. AIChE Journal, 60(6), 2211-2227.

Del Castillo, E. (2007). Process Optimization A Statistical Approach. Springer Science+Business Media, LLC (Vol. 480).

Del Castillo, E., \& Montgomery, D. C. (1993). A nonlinear programming solution to the dual response problem. Journal of Quality Technology, 25, 199-204.

Dellino, G. (2008). Robust Simulation-Optimization Methods using Kriging Metamodels.

Dellino, G., Kleijnen, Jack, P. C., \& Meloni, C. (2015). Metamodel-Based Robust Simulation-Optimization: An Overview. In In Uncertainty Management in Simulation-Optimization of Complex Systems (pp. 27-54).

Dellino, G., Kleijnen, J. P. C., \& Meloni, C. (2009). Robust simulation-optimization using metamodels. In Winter Simulation Conference (pp. 540-550).

Dellino, G., Kleijnen, J. P. C., \& Meloni, C. (2010a). Parametric and distribution-free bootstrapping in robust simulation-optimization. In Proceedings - Winter Simulation Conference (pp. 1283-1294).

Dellino, G., Kleijnen, J. P. C., \& Meloni, C. (2010). Robust optimization in simulation: Taguchi and Response Surface Methodology. International Journal of Production Economics, 125(1), 52-59.

Dellino, G., Kleijnen, J. P. C., \& Meloni, C. (2010b). Simulation-optimization under uncertainty through metamodeling and bootstrapping. Procedia - Social and Behavioral Sciences, 2(6), 7640-7641.

Dellino, G., Kleijnen, J. P. C., \& Meloni, C. (2012). Robust optimization in simulation: Taguchi and Krige combined. INFORMS Journal on Computing, 24(3), 471-484.

Dellino, G., Lino, P., Meloni, C., \& Rizzo, A. (2009). Kriging metamodel management in the design optimization of a CNG injection system. Mathematics and Computers in Simulation, 79(8), 2345-2360.

Dellino, G., \& Meloni, C. (2015). Uncertainty Management in Simulation- Optimization of Complex Systems.

Dellino, G., Meloni, C., \& Pierreval, H. (2014). Simulation-optimization of complex systems: Methods and applications. Simulation Modelling Practice and Theory, 46, 1-3.

Fang, K., Li, R. Z., \& Sudjianto, A. (2006). Design and modeling for computer experiments. Chapman $\{\&\}$ Hall/CRC Press.

Figueira, G., \& Almada-Lobo, B. (2014). Hybrid simulation optimization methods a taxonomy and discussion. 
Simulation Modelling Practice and Theory, 46, 118-134.

Forsberg, J., \& Nilsson, L. (2005). On polynomial response surfaces and Kriging for use in structural optimization of crashworthiness. Structural and Multidisciplinary Optimization, 29(3), 232-243.

Giunta, A. A., Dudley, J. M., Narducci, R., Grossman, B., Haftka, R. T., Mason, W. H., \& Watson, L. T. (1994). Noisy aerodynamic response and smooth approximations in HSCT design. In Proc. 5-th AIAA/USAF/NASA/ISSMO Symp. on Multidisciplinary and Structural Optimization (pp. 1117-1128).

Haftka, R. T., Villanueva, D., \& Chaudhuri, A. (2016). Parallel surrogate-assisted global optimization with expensive functions - a survey. Structural and Multidisciplinary Optimization, 54(1), 3-13.

Han, M., \& Yong Tan, M. H. (2016). Integrated parameter and tolerance design with computer experiments. IIE Transactions, 48(11), 1004-1015.

Havinga, J., van den Boogaard, A. H., \& Klaseboer, G. (2017). Sequential improvement for robust optimization using an uncertainty measure for radial basis functions. Structural and Multidisciplinary Optimization, 55(4), $1345-1363$.

He, Z., Wang, J., Jinho, O., \& H. Park, S. (2010). Robust optimization for multiple responses using response surface methodology. Applied Stochastic Models in Business and Industry, 26, 157-171.

Iman, R. L., \& Conover, W. J. (1982). A distribution-free approach to inducing rank correlation among input variab. Communications in Statistics - Simulation and Computation.

Jalali, H., \& Van Nieuwenhuyse, I. (2015). Simulation optimization in inventory replenishment: A classification. IIE Transactions, 47(11), 1217-1235.

Jang, H., \& Kim, H. (2014). Research output of science, technology and bioscience publications in Asia. Science Editing, 1(2), 62-70.

Javed, A., Pecnik, R., \& van Buijtenen, J. P. (2016). Optimization of a Centrifugal Compressor Impeller for Robustness to Manufacturing Uncertainties. Journal of Engineering for Gas Turbines and Power, 138(11).

Jin, R., Chen, W., \& Simpson, T. W. (2001). Comparative studies of metamodelling techniques under multiple modelling criteria. Structural and Multidisciplinary Optimization, 23(1), 1-13.

Jin, R., Du, X., \& Chen, W. (2003). The use of metamodeling techniques for optimization under uncertainty. Structural and Multidisciplinary Optimization, 25(2), 99-116.

Jurecka, F. (2007). Robust Design Optimization Based on Metamodeling Techniques. PhD Thesis.

Jurecka, F., Ganser, M., \& Bletzinger, K. U. (2007). Update scheme for sequential spatial correlation approximations in robust design optimisation. Computers and Structures, 85(10), 606-614.

Kamiński, B. (2015). Interval metamodels for the analysis of simulation Input-Output relations. Simulation Modelling Practice and Theory, 54, 86-100.

Khoshnevisan, S., Wang, L., \& Juang, C. H. (2017). Response surface based robust geotechnical design of supported excavation spreadsheet based solution. Georisk, 11(1), 90-102.

Kleijnen, J. P. C. (1993). Simulation and optimization in production planning. Decision Support Systems, 9(3), 269-280.

Kleijnen, J. P. C. (2005). An Overview of the Design and Analysis of Simulation Experiments for Sensitivity Analysis. European Journal of Operational Research, 164(2), 287-300. Retrieved from https://core.ac.uk/download/pdf/6651311.pdf

Kleijnen, J. P. C. (2009a). Factor screening in simulation experiments: Review of sequential bifurcation. In Advancing the frontiers of simulation (pp. 153-167).

Kleijnen, J. P. C. (2009b). Kriging metamodeling in simulation: A review. European Journal of Operational Research, 192(3), 707-716.

Kleijnen, J. P. C. (2010). Sensitivity analysis of simulation models: an overview. Procedia - Social and Behavioral Sciences, 2(6), 7585-7586.

Kleijnen, J. P. C. (2015). Design and analysis of simulation experiments (2nd). Springer.

Kleijnen, J. P. C. (2017). Regression and Kriging metamodels with their experimental designs in simulation - a review. European Journal of Operational Research, 256(1), 1-6.

Kleijnen, J. P. C., \& Beers, W. C. M. Van. (2004). Application-driven sequential designs for simulation experiments: Kriging metamodelling. Journal of the Operational Research Society, 55(8), 876-883.

Kleijnen, J. P. C., \& Gaury, E. (2003). Short-term robustness of production management systems: A case study. European Journal of Operational Research, 148(2), 452-465.

Kleijnen, J. P. C., \& van Beers, W. C. M. (2013). Monotonicity-preserving bootstrapped Kriging metamodels for expensive simulations. Journal of the Operational Research Society, 64(5), 708-717.

Krige, D. G. (1951). A statistical approach to some mine valuation and allied problems on the Witwatersrand. Journal of the Chemical, Metallurgical and Mining Society of South Africa.

Kuhnt, S., \& Steinberg, D. M. (2010). Design and analysis of computer experiments. AStA Advances in Statistical 
Analysis, 94(4), 307-309.

Lehman, J. S., Santner, T. J., \& Notz, W. I. (2004). Designing Computer Experiments To Determine Robust Control Variables. Statistica Sinica, 14(1), 571-590.

Leotardi, C., Serani, A., Iemma, U., Campana, E. F., \& Diez, M. (2016). A variable-accuracy metamodel-based architecture for global MDO under uncertainty. Structural and Multidisciplinary Optimization, 54(3), 573593.

Li, M., Yang, F., Uzsoy, R., \& Xu, J. (2016). A metamodel-based Monte Carlo simulation approach for responsive production planning of manufacturing systems. Journal of Manufacturing Systems, 38, $114-133$.

Li, Y. F., Ng, S. H., Xie, M., \& Goh, T. N. (2010). A systematic comparison of metamodeling techniques for simulation optimization in Decision Support Systems. Applied Soft Computing, 10(4), 1257-1273.

Lophaven, S. N., Nielsen, H. B., \& Søndergaard, J. (2002). DACE - A Matlab Kriging Toolbox (Version 2.0). Technical Report IMM-REP-2002-12, Informatics and Mathematical Modelling, DTU.

McKay, M. D., Beckman, R. J., \& Conover, W. J. (1979). Comparison of three methods for selecting values of input variables in the analysis of output from a computer code. Technometrics, 21(2), 239-245.

Moghaddam, S., \& Mahlooji, H. (2016). Robust simulation optimization using \$ $\varphi$ \$-divergence. International Journal of Industrial Engineering Computations, 7(4), 517-534.

Mohammad Nezhad, A., \& Mahlooji, H. (2013). An artificial neural network meta-model for constrained simulation optimization. Journal of the Operational Research Society, 65(8), 1232-1244.

Myers, R., C.Montgomery, D., \& Anderson-Cook, M, C. (2016). Response Surface Methodology: Process and Product Optimization Using Designed Experiments-Fourth Edittion. John Wiley \& Sons.

Neelamkavil, F. (1987). Computer simulation and modelling. John Wiley $\{\&\}$ Sons, Inc.

Nha, V. T., Shin, S., \& Jeong, S. H. (2013). Lexicographical dynamic goal programming approach to a robust design optimization within the pharmaceutical environment. European Journal of Operational Research, 229(2), 505-517.

Park, S., \& Antony, J. (2008). Robust design for quality engineering and six sigma. World Scientific.

Parnianifard, A., Azfanizam, A. S., Ariffin, M. K. A., \& Ismail, M. I. S. (2018). An overview on robust design hybrid metamodeling: Advanced methodology in process optimization under uncertainty. International Journal of Industrial Engineering Computations, 9(1), 1-32.

Peri, D., \& Tinti, F. (2012). A multistart gradient-based algorithm with surrogate model for global optimization. Communications in Applied and Industrial Mathematics, 3(1), 1-22.

Phadke, M. S. (1989). Quality Engineering Using Robust Design. Prentice Hall PTR.

Rutten, K. (2015). Methods For Online Sequential Process Improvement. PhD Thesis.

Sanchez, S. M. (2000). Robust design: Seeking the best of all possible worlds. In In: Joines, J.A., Barton, R.R., Kang, K., Fishwick, P.A. (eds.) Proceedings of the Winter Simulation Conference (Vol. 1, pp. 69-76).

Sathishkumar, L., \& Venkateswaran, J. (2016). Impact of input data parameter uncertainty on simulation-based decision making. In IEEE International Conference on Industrial Engineering and Engineering Management (pp. 1267-1271).

Shan, S., \& Wang, G. G. (2010). Survey of modeling and optimization strategies to solve high-dimensional design problems with computationally-expensive black-box functions. Structural and Multidisciplinary Optimization, 41(2), 219-241.

Simpson, T., Booker, A., Ghosh, D., Giunta, A. A., Koch, P. N., \& Yang, R.-J. (2004). Approximation methods in multidisciplinary analysis and optimization: a panel discussion. Structural andMultidisciplinary Optimization, 27(5), 302-313.

Simpson, T. W., Mauery, T. M., Korte, J., \& Mistree, F. (2001). Kriging models for global approximation in simulation-based multidisciplinary design optimization. AIAA Journal, 39(12), 2233-2241.

Simpson, T. W., Poplinski, J. D., Koch, P. N., \& Allen, J. K. (2001). Metamodels for Computer-based Engineering Design: Survey and recommendations. Engineering With Computers, 17(2), 129-150.

Sóbester, A., Leary, S. J., \& Keane, A. J. (2004). A parallel updating scheme for approximating and optimizing high fidelity computer simulations. Structural and Multidisciplinary Optimization, 27(5), 371-383.

Sreekanth, J., Moore, C., \& Wolf, L. (2016). Pareto-based efficient stochastic simulation-optimization for robust and reliable groundwater management. Journal of Hydrology, 533, 180-190.

Steenackers, G., Guillaume, P., \& Vanlanduit, S. (2009). Robust Optimization of an Airplane Component Taking into Account the Uncertainty of the Design Parameters. Quality and Reliability Engineering International, 25(3), 255-282.

Stinstra, E., \& den Hertog, D. (2008). Robust optimization using computer experiments. European Journal of Operational Research, 191(3), 816-837.

Taflanidis, A. A., \& Medina, J. C. (2015). Simulation-Based Optimization in Design-Under-Uncertainty 
Problems Through Iterative Development of Metamodels in Augmented Design/Random Variable Space. In Simulation and Modeling Methodologies, Technologies and Applications (Vol. 402, pp. 251-273). Springer.

Teleb, R., \& Azadivar, F. (1994). A methodology for solving multi-objective simulatlon-optimization problems. European Journal of Operational Research, 72, 135-145.

Truong, H. T., \& Azadivar, F. (2003). Simulation based optimization for supply chain configuration design. In Winter simulation conference (pp. 1268-1275).

Uddameri, V., Hernandez, E. A., \& Estrada, F. (2014). A fuzzy simulation-optimization approach for optimal estimation of groundwater availability under decision maker uncertainty. Environmental Earth Sciences, 71(6), 2559-2572.

van Beers, W. C. M., \& Kleijnen, J. P. C. (2003). Kriging for interpolation in random simulation. Journal of the Operational Research Society, 54(3), 255-262.

Van Beers, W. C. M., \& Kleijnen, J. P. C. (2004). Kriging Interpolation in Simulation: A Survey. Proceedings of the 2004 Winter Simulation Conference, 2004., 1, 107-115.

Viana, F. A. C., Simpson, T. W., Balabanov, V., \& Toropov, V. (2014). Metamodeling in Multidisciplinary Design Optimization: How Far Have We Really Come? AIAA Journal, 52(4), 670-690.

Vining, G., \& Myers, R. (1990). Combining Taguchi and response surface philosophies- A dual response approach. Journal of Quality Technology, 22(1), 38-45.

Wang, G. G. (2003). Adaptive Response Surface Method Using Inherited Latin Hypercube Design Points. Journal of Mechanical Design, 125(2), 210-220.

Wang, G., \& Shan, S. (2007). Review of Metamodeling Techniques in Support of Engineering Design Optimization. Journal of Mechanical Design, 129(4), 370-380.

Wiebenga, J. H., Van Den Boogaard, A. H., \& Klaseboer, G. (2012). Sequential robust optimization of a Vbending process using numerical simulations. Structural and Multidisciplinary Optimization, 46(1), $137-$ 153.

Williams, B., Higdon, D., Gattiker, J., Moore, L., McKay, M., \& Keller-McNulty, S. (2006). Combining experimental data and computer simulations, with an application to flyer plate experiments. Bayesian Analysis, 1(4), 765-792.

Wim, C. ., Beers, V., \& Kleijnen, J. P. C. (2008). Customized sequential designs for random simulation experiments: Kriging metamodeling and bootstrapping. European Journal of Operational Research, 186(3), 1099-1113.

Yanikoglu, I., Hertog, D. Den, \& Kleijnen, J. P. C. (2016). Robust Dual Response Optimization. IIE Transactions, 48(3), 298-312.

Zhang, J., Chowdhury, S., Zhang, J., Messac, A., \& Castillo, L. (2013). Adaptive Hybrid Surrogate Modeling for Complex Systems. AIAA Journal, 51(3), 643-656.

Zhang, J. L., Li, Y. P., \& Huang, G. H. (2014). A robust simulation-optimization modeling system for effluent trading-a case study of nonpoint source pollution control. Environmental Science and Pollution Research, 21(7), 5036-5053.

Zhang, J., Taflanidis, A. A., \& Medina, J. C. (2017). Sequential approximate optimization for design under uncertainty problems utilizing Kriging metamodeling in augmented input space. Computer Methods in Applied Mechanics and Engineering, 315, 369-395.

Zhou, H., Zhou, Q., Liu, C., \& Zhou, T. (2017). A Kriging metamodel-assisted robust optimization method based on a reverse model. Engineering Optimization, 1-20.

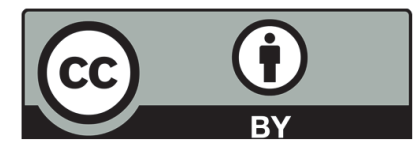

(C) 2019 by the authors; licensee Growing Science, Canada. This is an open access article distributed under the terms and conditions of the Creative Commons Attribution (CC-BY) license (http://creativecommons.org/licenses/by/4.0/). 